\title{
Separation and Purification of Berkelium-249 and Einsteinium-254
}

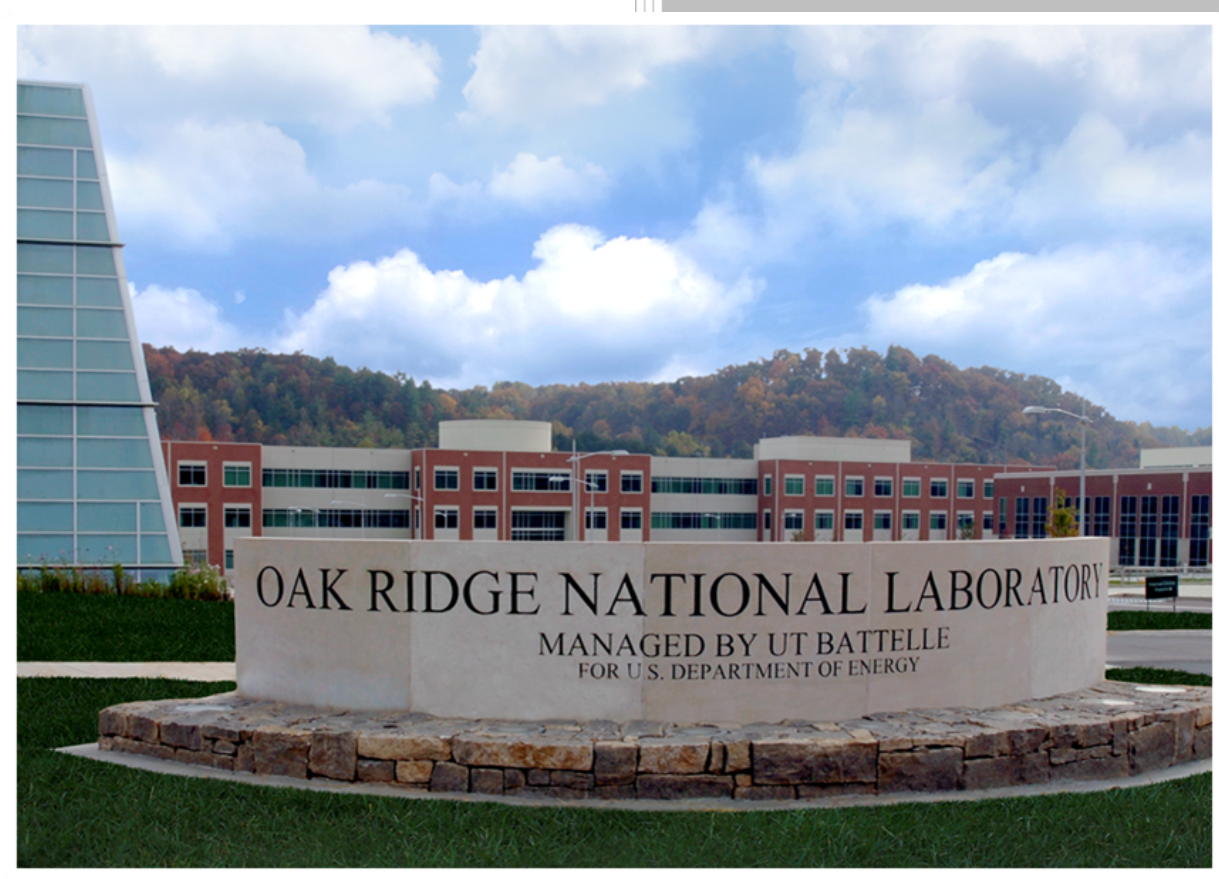
R. A. Boll
T. A. Dyer
J. G. Ezold
C. E. Phelps
K. M. Phillips
C. E. Porter
J. L. Rayburn
F. D. Riley
N. J. Sims
S. M. Van Cleve

Approved for public release.

Distribution is unlimited.

January 2020 


\section{DOCUMENT AVAILABILITY}

Reports produced after January 1, 1996, are generally available free via US Department of Energy (DOE) SciTech Connect.

Website www.osti.gov

Reports produced before January 1, 1996, may be purchased by members of the public from the following source:

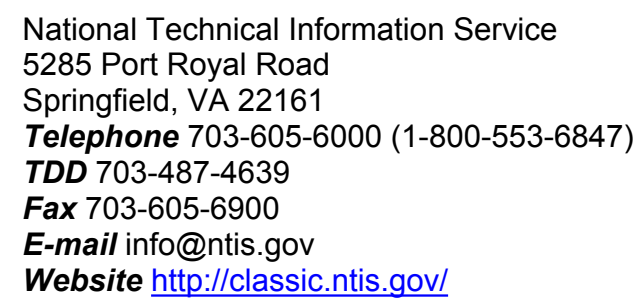

Reports are available to DOE employees, DOE contractors, Energy Technology Data Exchange representatives, and International Nuclear Information System representatives from the following source:

Office of Scientific and Technical Information

PO Box 62

Oak Ridge, TN 37831

Telephone 865-576-8401

Fax 865-576-5728

E-mail reports@osti.gov

Website http://www.osti.gov/contact.html

This report was prepared as an account of work sponsored by an agency of the United States Government. Neither the United States Government nor any agency thereof, nor any of their employees, makes any warranty, express or implied, or assumes any legal liability or responsibility for the accuracy, completeness, or usefulness of any information, apparatus, product, or process disclosed, or represents that its use would not infringe privately owned rights. Reference herein to any specific commercial product, process, or service by trade name, trademark, manufacturer, or otherwise, does not necessarily constitute or imply its endorsement, recommendation, or favoring by the United States Government or any agency thereof. The views and opinions of authors expressed herein do not necessarily state or reflect those of the United States Government or any agency thereof. 
Isotope and Fuel Cycle Technology Division

Separation and Purification of Berkelium-249 and Einsteinium-254

\author{
Authors: \\ R. A. Boll \\ T. A. Dyer \\ J. G. Ezold \\ C. E. Phelps \\ K. M. Phillips \\ C. E. Porter \\ J. L. Rayburn \\ F. D. Riley \\ N. J. Sims \\ S. M. Van Cleve
}

Date Published: January 2020

Prepared by

OAK RIDGE NATIONAL LABORATORY

Oak Ridge, TN 37831-6283

managed by

UT-BATTELLE, LLC

for the

US DEPARTMENT OF ENERGY

under contract DE-AC05-00OR22725 



\section{CONTENTS}

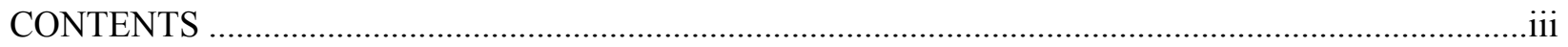

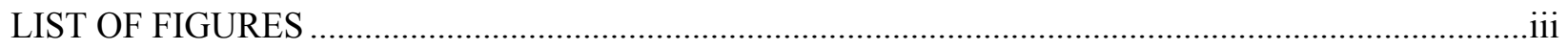

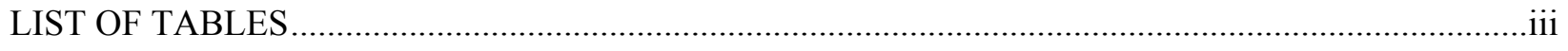

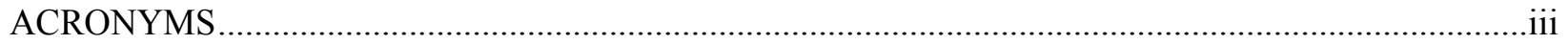

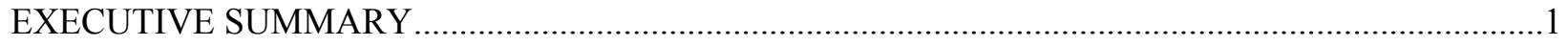

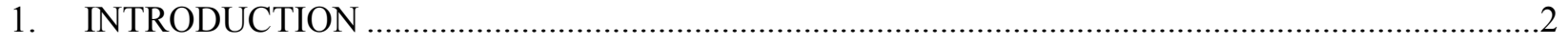

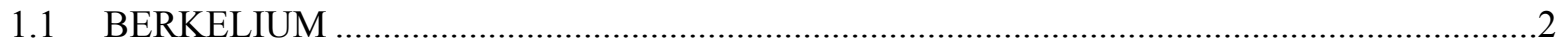

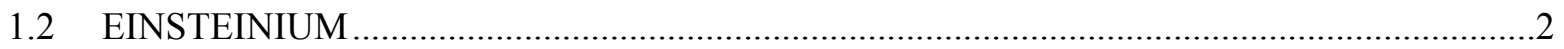

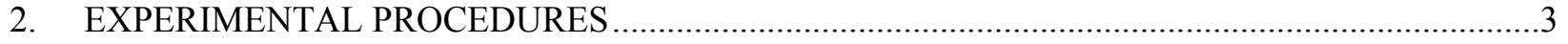

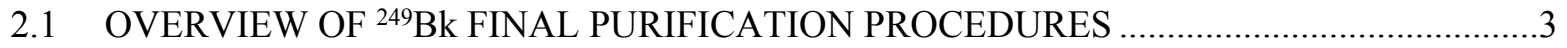

2.1.1 Organic Solvent Scrubbing with Trichloroethylene (TCE) ..........................................

2.1.2 Volume Reduction and Cation-Exchange Feed Preparation.........................................

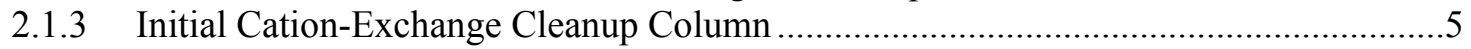

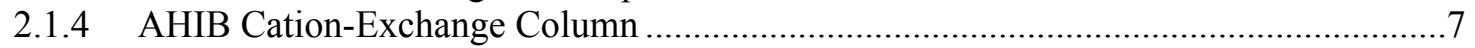

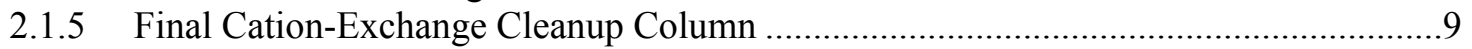

2.2. OVERVIEW OF ${ }^{254}$ Es FINAL PURIFICATION PROCEDURES .......................................12

2.2.1. Initial Cation-Exchange Concentrator Column ........................................................12

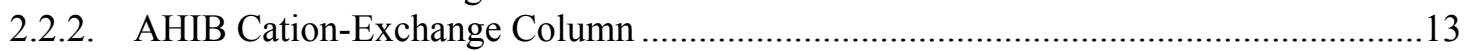

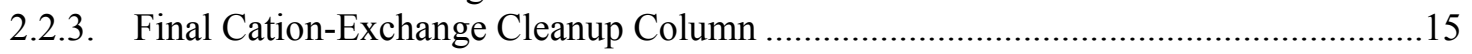

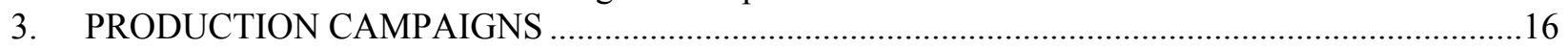

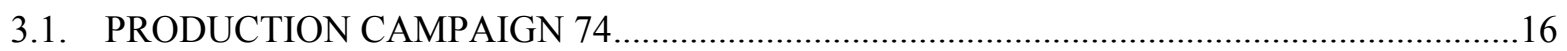

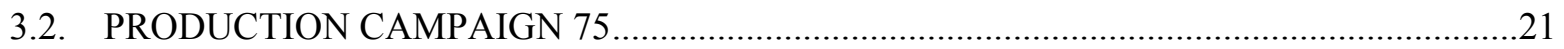

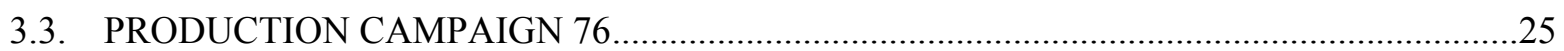

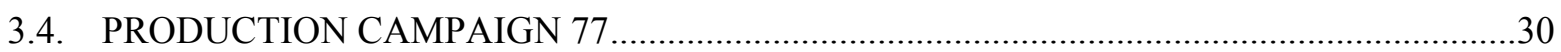

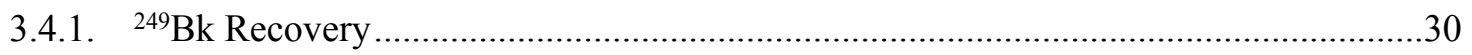

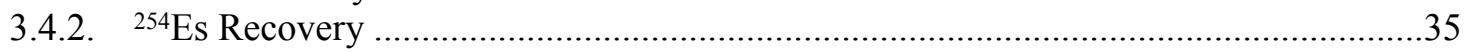

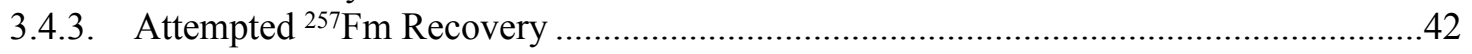

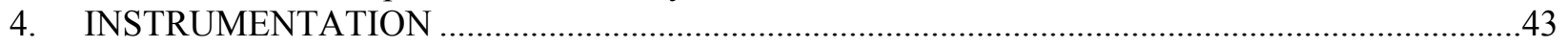

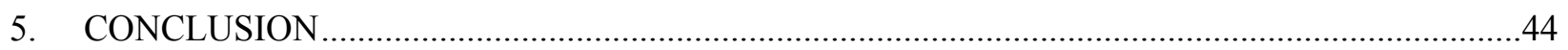

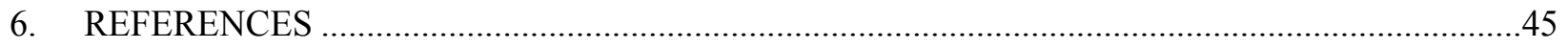

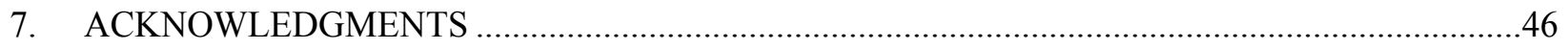




\section{LIST OF FIGURES}

Figure 1. Organic and aqueous layers in separatory funnel during TCE scrubbing. ................................4

Figure 2. Condensation and reflux condenser unit with heating mantle ..................................................

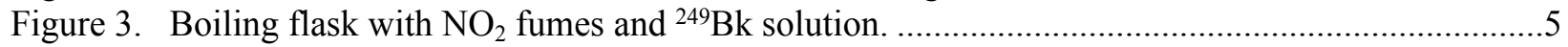

Figure 4. Initial cation-exchange cleanup column with $150 \mathrm{~mL}$ reservoir, showing elution into

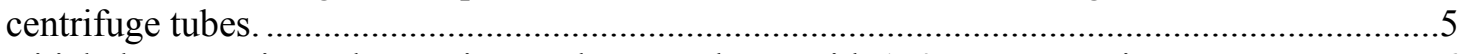

Figure 5. Initial cleanup micro-glass cation-exchange column with $150 \mathrm{~mL}$ reservoir...........................6

Figure 6. The ${ }^{249} \mathrm{Bk}$ product with "Bk green" color in centrifuge tube, before and after volume

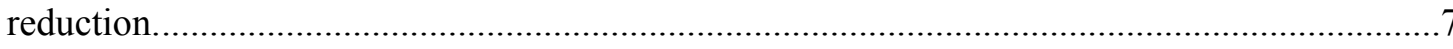

Figure 7. Micro-glass jacketed AHIB cation-exchange column........................................................

Figure 8. AHIB column loaded with ${ }^{249} \mathrm{Bk}$ solution, showing movement of green band.........................9

Figure 9. Final cleanup micro-glass cation-exchange column.....................................................11

Figure 10. Final cation-exchange cleanup column with ${ }^{249} \mathrm{Bk}$ solution loaded onto resin. ........................12

Figure 11. Initial cation-exchange concentrator column with ${ }^{254} \mathrm{Es}$ product in a centrifuge tube

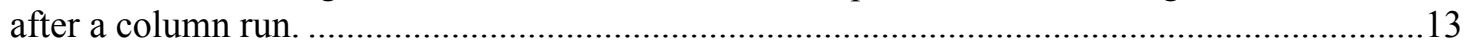

Figure 12. AHIB column loaded with ${ }^{254}$ Es solution and the centrifuge containing the product...............14 


\section{LIST OF TABLES}

Table 1. Summary of purified ${ }^{249} \mathrm{Bk}$ and ${ }^{254} \mathrm{Es}$ harvested in Cf Campaigns 74 and 77 ...........................1

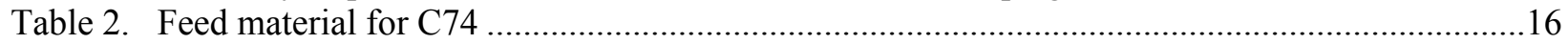

Table 3. Dose rates and volumes of centrifuge tubes 1-8 from AHIB column separation ......................17

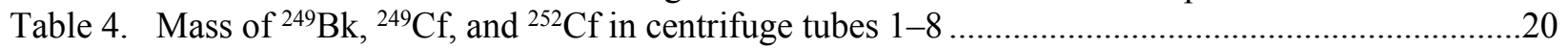

Table 5. Analysis of ${ }^{249} \mathrm{Bk}$ solution after final cleanup procedures ....................................................20

Table 6. Dose rates and volumes of quartz cones sent to customers in Dimitrovgrad, Russia..................21

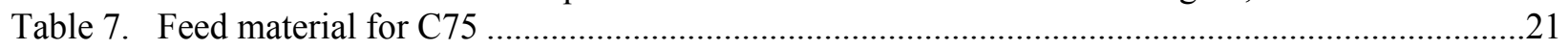

Table 8. Dose rates and volume of centrifuge tubes 1 and 2 after volume reduction.............................22

Table 9. Dose rates and volumes of centrifuge tubes 3-6 after initial cleanup column ..........................22

Table 10. Dose rates and volumes of centrifuge tubes 7-20 from AHIB column separation ....................23

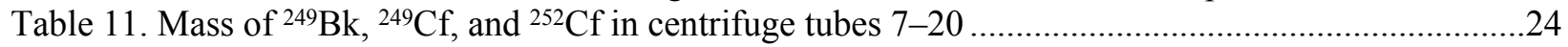

Table 12. Analysis of ${ }^{249} \mathrm{Bk}$ solution after final cleanup procedures ..................................................24

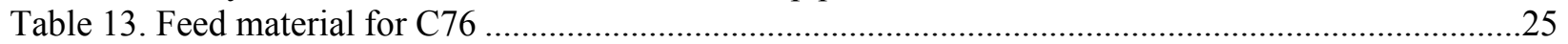

Table 14. Dose rates and volume of CT1 and CT2 after volume reduction ............................................26

Table 15. Dose rates and volumes of CT1 and CT2 after initial cleanup column ...................................26

Table 16. Dose rates and volumes of centrifuge tubes 4-9 from AHIB column separation ......................27

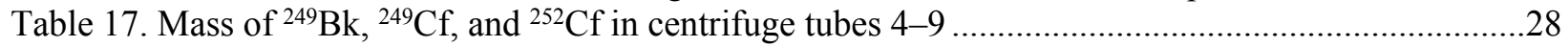

Table 18. Dose rates and volumes of centrifuge tubes 10 and 11 after final cleanup column....................28

Table 19. Dose rates and volumes of centrifuge tubes 12 and 13 after final cleanup column....................29

Table 20. Analysis of ${ }^{249} \mathrm{Bk}$ solution after final cleanup procedures .......................................................29

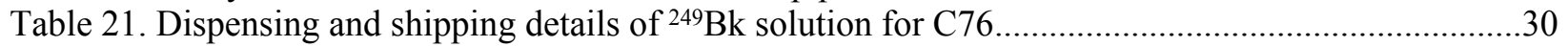

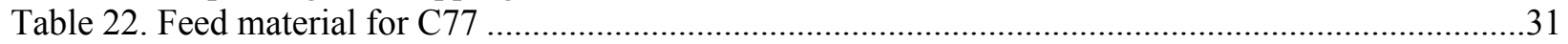

Table 23. Dose rates and volumes of CT1 and CT2 after volume reduction..........................................31

Table 24. Dose rates and volumes of centrifuge tubes $3-10$ after initial cleanup column .........................32

Table 25. Dose rates and volumes of centrifuge tubes 11-17 and FLR after AHIB separation..................33

Table 26. Mass of ${ }^{249} \mathrm{Bk},{ }^{249} \mathrm{Cf}$, and ${ }^{252} \mathrm{Cf}$ in centrifuge tubes $11-17$ after AHIB separation.......................33

Table 27. Dose rates and volumes of centrifuge tubes 18-20 after final cleanup column .........................34

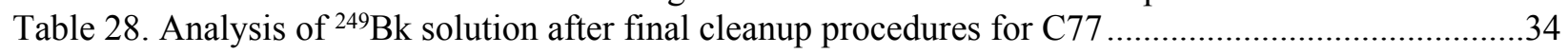

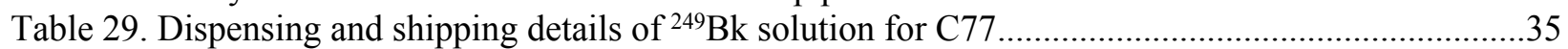

Table 30. Dose rates and volumes of centrifuge tubes 1-5 after concentrator cation-exchange

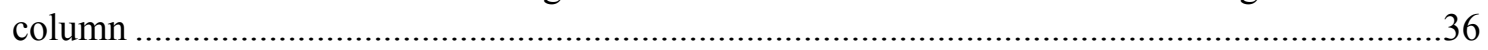

Table 31. Dose rates and volumes of centrifuge tubes 6-19 after first AHIB column ..............................37

Table 32. Dose rates and volumes of centrifuge tubes 20-31 after second AHIB column .........................38

Table 33. Dose rates and volumes of centrifuge tubes $32-45$ after third AHIB column............................39

Table 34. Dose rates and volumes of centrifuge tubes 46-60 after fourth AHIB column..........................40

Table 35. Dose rates and volumes of centrifuge tubes $61-66$ after final cation-exchange column.............41

Table 36. Analysis of ${ }^{254}$ Es solution after final cleanup procedures ..........................................................4

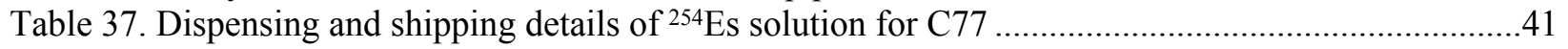

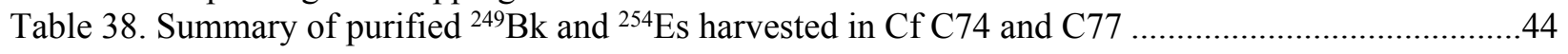




\section{ACRONYMS}

$\begin{array}{ll}\text { AHIB } & \text { alpha-hydroxy-isobutyrate } \\ \text { C74 } & \text { Campaign } 74 \\ \text { C75 } & \text { Campaign 75 } \\ \text { C76 } & \text { Campaign 76 } \\ \text { C77 } & \text { Campaign 77 } \\ \text { CT } & \text { centrifuge tube } \\ \text { FLR } & \text { feed/load/raffinate } \\ \text { HFIR } & \text { High Flux Isotope Reactor } \\ \text { ORNL } & \text { Oak Ridge National Laboratory } \\ \text { REDC } & \text { Radiochemical Engineering Development Center } \\ \text { TCE } & \text { trichloroethylene }\end{array}$




\section{EXECUTIVE SUMMARY}

Berkelium-249 $\left({ }^{249} \mathrm{Bk}\right)$ and einsteinium-254 $\left({ }^{254} \mathrm{Es}\right)$ are isotopes of great importance for the investigation of berkelium and einsteinium chemical properties and super heavy element research. Therefore, it is necessary to be able to isolate acceptable, pure quantities of both isotopes to further research capabilities. These isotopes, along with californium-252 $\left({ }^{252} \mathrm{Cf}\right)$, are synthesized through the irradiation of mixed-curium targets in the High Flux Isotope Reactor (HFIR), which has the highest continuous thermal neutron flux in the world. Once irradiated, the targets are transferred to the Radiochemical Engineering Development Center for further chemical processing and final purification to separate ${ }^{249} \mathrm{Bk}$ and ${ }^{254} \mathrm{Es}$ from the remainder of isotopes present. Several methods of separation, such as the Berkex batch solvent extraction along with cation-exchange and alpha-hydroxy-isobutyrate (AHIB) columns, are employed to achieve a clean separation of the isotopes. Production Campaigns $74-77$ are discussed in depth for ${ }^{252} \mathrm{Cf},{ }^{249} \mathrm{Bk}$, and ${ }^{254} \mathrm{Es}$ production and isolation of ${ }^{249} \mathrm{Bk}$ and ${ }^{254} \mathrm{Es}$. An attempt to isolate ${ }^{257} \mathrm{Fm}$ in Campaign 77 is discussed as well. Table 1 summarizes the total amount of material isolated in each campaign.

Table 1. Summary of purified ${ }^{249} \mathrm{BK}$ and ${ }^{254} \mathrm{Es}$ harvested in Cf Campaigns 74 through 77

\begin{tabular}{c|c|c|c}
\hline $\begin{array}{c}\text { Production } \\
\text { Campaign }\end{array}$ & Year & $\begin{array}{c}{ }^{249} \mathbf{B k} \\
\text { Harvested, } \\
\mathbf{m g}\end{array}$ & $\begin{array}{c}{ }^{254} \mathbf{E s} \\
\text { Harvested, } \\
\boldsymbol{\mu g}\end{array}$ \\
\hline 74 & $2008-2009$ & 22.2 & N/A \\
\hline 75 & $2011-2012$ & 26.6 & N/A \\
\hline 76 & $2014-2015$ & 13.5 & N/A \\
\hline 77 & $2016-2017$ & 10.3 & 1.08 \\
\hline
\end{tabular}




\section{INTRODUCTION}

\subsection{BERKELIUM}

Element 97 was discovered in 1949 at the Berkeley Crocker Laboratory by cyclotron bombardment of americium-241 $\left({ }^{241} \mathrm{Am}\right)$ with accelerated alpha particles. Named after the city of its discovery, the new element berkelium was assigned an isotope with a mass number of 243 . In $1958,{ }^{249} \mathrm{Bk}$ was isolated by neutron irradiation of plutonium-239 $\left({ }^{239} \mathrm{Pu}\right)$ to help improve the investigation of berkelium chemical properties. Although tracer experiments using ${ }^{243} \mathrm{Bk}$, half-life of 4.5 hours, were used to study the stability of $\mathrm{Bk}(\mathrm{III})$ and $\mathrm{Bk}(\mathrm{IV})$, the isolation of ${ }^{249} \mathrm{Bk}$ was used to determine the absorption spectrum and magnetic susceptibility of Bk(III). Berkelium-249 is still primarily used for chemical studies due to its availability and longer half-life of 330 days compared to the other isotopes of berkelium [1].

Today, there are 15 known isotopes of berkelium with mass numbers ranging from 234 to 253 . Due to its longer half-life, ${ }^{249} \mathrm{Bk}$ is the only isotope available in larger quantities. Much of the isotope's production is supplied from the irradiation of target rods consisting of mixed curium isotopes to produce ${ }^{252} \mathrm{Cf}$ in the High Flux Isotope Reactor (HFIR) at Oak Ridge National Laboratory (ORNL). In 2010, the discovery of element 117 , tennessine, was accomplished by the fusion reaction between calcium- $48\left({ }^{48} \mathrm{Ca}\right)$ and ${ }^{249} \mathrm{Bk}$ with neutron emission [2]. The ${ }^{249} \mathrm{Bk}$ feed material that was used to accomplish the fusion reaction was supplied from the fraction of berkelium separated and purified from the ${ }^{252} \mathrm{Cf}$ production efforts at ORNL in Campaign 74 (C74). The Bk material from Campaign 75 (C75) was used to verify the discovery of Tn, and the Bk fraction from Campaigns 76 and 77 (C76 and C77) were used for various Bk chemical studies. The isolation of ${ }^{249} \mathrm{Bk}$ is necessary to continue the investigations of berkelium chemical properties and the continuation of super heavy element research. Herein, the separation and purification of ${ }^{249} \mathrm{Bk}$ throughout the ${ }^{252} \mathrm{Cf}$ production campaigns will be discussed in depth.

\subsection{EINSTEINIUM}

Named after Albert Einstein, Element 99 was first discovered on December 19, 1952, by A. Ghiorso et al. through the "Mike" thermonuclear weapon explosion on November 1, 1952. The synthesis of the Element 99 was accomplished by exposing a uranium source to the high neutron flux from the explosion resulting in the discovery of both Element 99 and 100. Although the discovery took place in 1952, the work could not be published until 1955 because it was classified. The first isotopic mass identified for einsteinium was 253 by the beta decay of uranium-253 $\left({ }^{253} \mathrm{U}\right)$ to ${ }^{253} \mathrm{Cf}$ and subsequently the beta decay of ${ }^{253} \mathrm{Cf}$ to ${ }^{253} \mathrm{Es}$ [3]. The first published einsteinium isotope was credited to ${ }^{246} \mathrm{Es}$ in 1953 by Ghiorso et al. The team made sure to not claim the work as the discovery, releasing this statement: "There is unpublished information relevant to element 99 at the University of California, Argonne National Laboratory, and Los Alamos Scientific Laboratory. Until this information is published the question of the first preparation should not be prejudged on the basis of this paper." After the discovery of ${ }^{246}$ Es and ${ }^{253} \mathrm{Es}$, the production of several einsteinium isotopes with mass numbers ranging from 249 to 252 was published in 1956 by Harvey et al. The production of the new isotopes was accomplished through the cyclotron bombardment of ${ }^{249} \mathrm{Bk}$ with helium ions [4].

Today, there are 17 known einsteinium isotopes with mass numbers ranging from 241 to 257 . Because of its limited availability and shorter isotopic half-lives, einsteinium does not have many applications other than for basic research purposes and production of other heavy transuranic elements. However, in 1955, the element mendelevium was synthesized by bombarding ${ }^{253}$ Es with helium ions [5]. Other applications include in-beam fission studies using ${ }^{254}$ Es with the Tandem accelerator at the Japan Atomic Energy Agency and einsteinium characterization by Florida State University. In the following sections, the separation and purification of ${ }^{254}$ Es during ORNL ${ }^{252} \mathrm{Cf}$ Production $\mathrm{C} 77$ will be discussed in depth for use in continuing einsteinium research. 


\section{EXPERIMENTAL PROCEDURES}

\subsection{OVERVIEW OF ${ }^{249}$ BK FINAL PURIFICATION PROCEDURES}

All experimental work and processing steps for ${ }^{249} \mathrm{Bk}$ production were conducted in the REDC at ORNL in Oak Ridge, Tennessee. The procedures listed below outline the processes performed for the final purification efforts of ${ }^{249} \mathrm{Bk}$ in ${ }^{252} \mathrm{Cf}$ Production Campaigns 74, 75, 76, and 77. Mixed curium targets were irradiated in HFIR primarily for ${ }^{252} \mathrm{Cf}$ production. However, the irradiation produces other actinide elements, including ${ }^{249} \mathrm{Bk}$. Once irradiated, the $\mathrm{Cm}$ targets are transferred into REDC hot cells for dissolution and separation of actinide elements. A series of processing steps-such as the Cleanex batch solvent extraction process, $\mathrm{LiCl}$ anion exchange, $\mathrm{LiOH}$ precipitation, and alpha-hydroxy-isobutyrate (AHIB) column separation - separates the ${ }^{252} \mathrm{Cf}$ product and the $\mathrm{Cm}$ target material. Once the bulk of the $\mathrm{Cf}$ and $\mathrm{Cm}$ are separated, the purification processes specifically for Bk purification begin with the Berkex batch solvent extraction process.

The Berkex batch solvent extraction process is used to concentrate and purify berkelium from californium and other actinide/lanthanide impurities. This process is initiated by the oxidization of Bk(III) to Bk(IV) using $2 \mathrm{M}$ sodium bromate $\left(\mathrm{NaBrO}_{3}\right)$. Since most actinides and lanthanides, including californium, cannot oxidize to the +4 state, this makes separation of berkelium from the majority of residual contaminants possible by a difference in oxidation states. Once oxidized, the Bk(IV) is extracted into an organic layer using $0.5 \mathrm{M}$ bis-(2-ethylhexyl) phosphoric acid in dodecane, while the residual californium and other contaminants are left in the aqueous layer. The next step of the solvent extraction process involves the scrubbing (washing) of $\mathrm{Bk}(\mathrm{IV})$ to remove residual ${ }^{252} \mathrm{Cf}$ with an $8 \mathrm{M} \mathrm{HNO}_{3}-0.3 \mathrm{M} \mathrm{NaBrO}$ solution. The scrubbing followed by the removal, or stripping, of $\mathrm{Bk}(\mathrm{IV})$ from the organic to the aqueous phase is completed by the reduction of $\mathrm{Bk}(\mathrm{IV})$ to $\mathrm{Bk}$ (III) with $8 M \mathrm{HNO}_{3}$ containing $1 M \mathrm{H}_{2} \mathrm{O}_{2}$. From there, an aqueous solution containing the ${ }^{249} \mathrm{Bk}$ and trace ${ }^{252} \mathrm{Cf}$ is transferred into a shielded glovebox for final cleanup efforts.

\subsubsection{Organic Solvent Scrubbing with Trichloroethylene (TCE)}

To remove organic dodecane impurities from the aqueous $\mathrm{HNO}_{3}$ solution containing ${ }^{249} \mathrm{Bk}$ and residual ${ }^{252} \mathrm{Cf}$, an organic solvent scrubbing with trichloroethylene (TCE) in three separate volumes of around $300 \mathrm{~mL}$ each is necessary. This is accomplished by swirling both the aqueous and organic layers in a polyethylene bottle for 15 minutes to allow proper contact between the two layers. After proper mixing is ensured, the two phases are transferred to a separatory funnel and allowed to separate for 45 minutes (Figure 1). The organic layer is drained into a collection bottle, and a fresh $300 \mathrm{~mL}$ of TCE and the aqueous layer is mixed again in a separate polyethylene bottle. This process is repeated for a second time to ensure proper mixing and separation. The same procedure is repeated with a third volume of TCE, allowing the phases to separate for 12 hours for the last scrubbing. The aqueous layer is extracted using a separatory funnel, and the excess organic solution is discarded. 


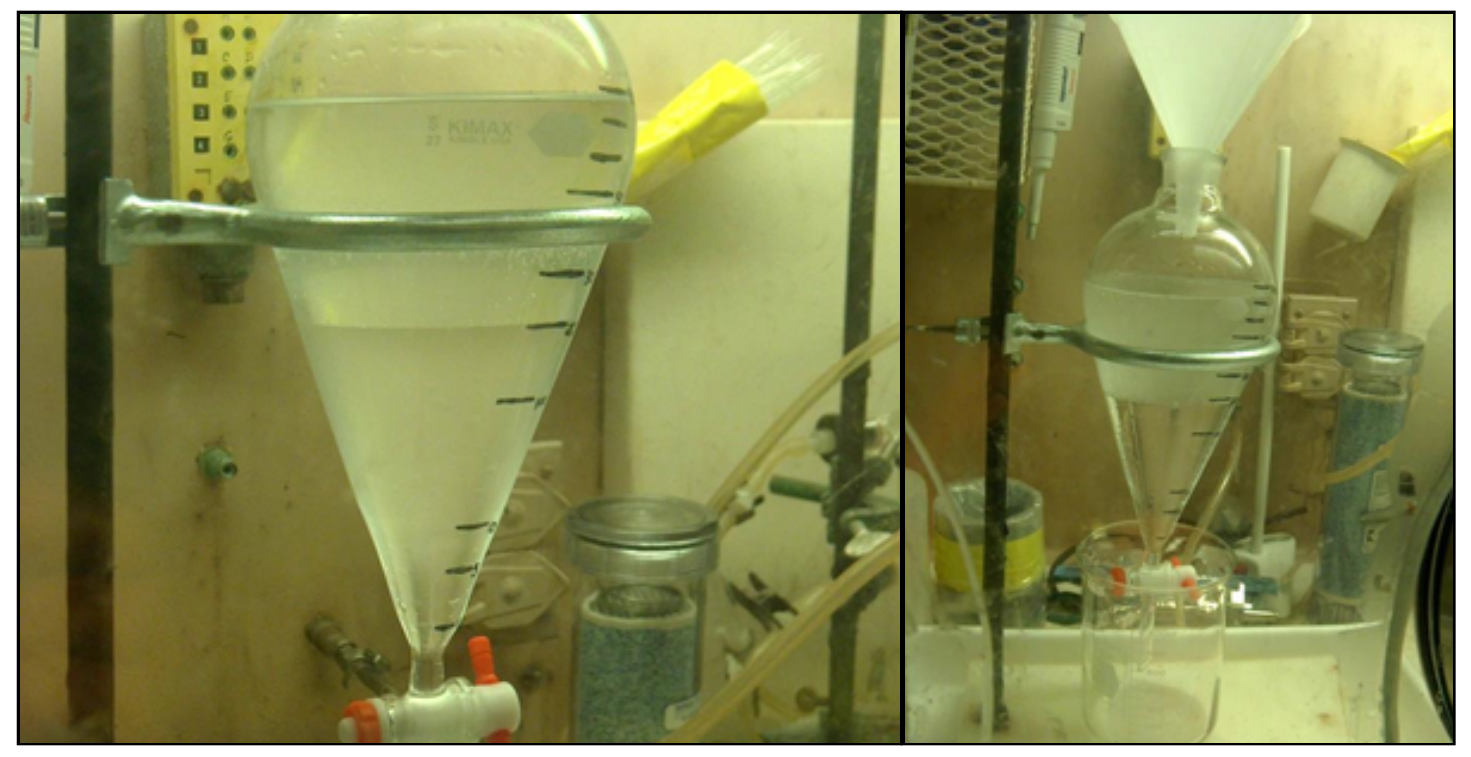

Figure 1. Organic (bottom) and aqueous (top) layers in separatory funnel during TCE scrubbing.

\subsubsection{Volume Reduction and Cation-Exchange Feed Preparation}

A condensation unit with a reflux condenser and heating mantle is used for volume reduction of the aqueous phase and any remnants of organic solvent from the organic scrubbing (Figure 2). A refrigerated water bath for the reflux condenser is maintained at $16^{\circ} \mathrm{C}$. Partial volumes of the aqueous solution are transferred to a $500 \mathrm{~mL}$ round bottom boiling flask. The refluxed volume is collected in a condensate bottle. After boiling the solution down to $50-100 \mathrm{~mL}$, the aqueous solution remaining in the boiling flask is allowed to cool before adding additional volume to reduce (Figure 3). Brown nitrogen dioxide gas is present during this process because of the decomposition of nitric acid. After the necessary volume is distilled off, $\sim 5 \mathrm{~mL}$ of the green-colored solution is transferred to a $15 \mathrm{~mL}$ centrifuge tube. The dose rates and final volumes are recorded. The molarity of the aqueous solution is then adjusted to around $0.2 \mathrm{M}$ in preparation for loading onto a cation-exchange cleanup column, using a strong cation-exchange resin. To limit contamination of the aqueous solution, ultra-pure water is used to adjust the acidity concentration.

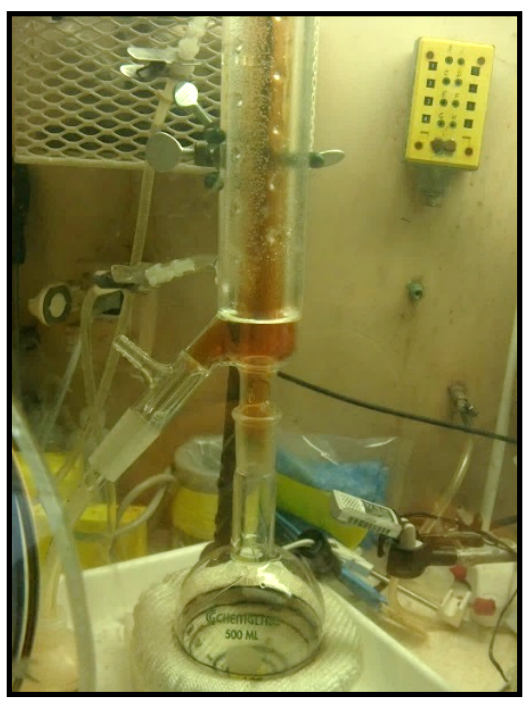

Figure 2. Condensation and reflux condenser unit with heating mantle. 


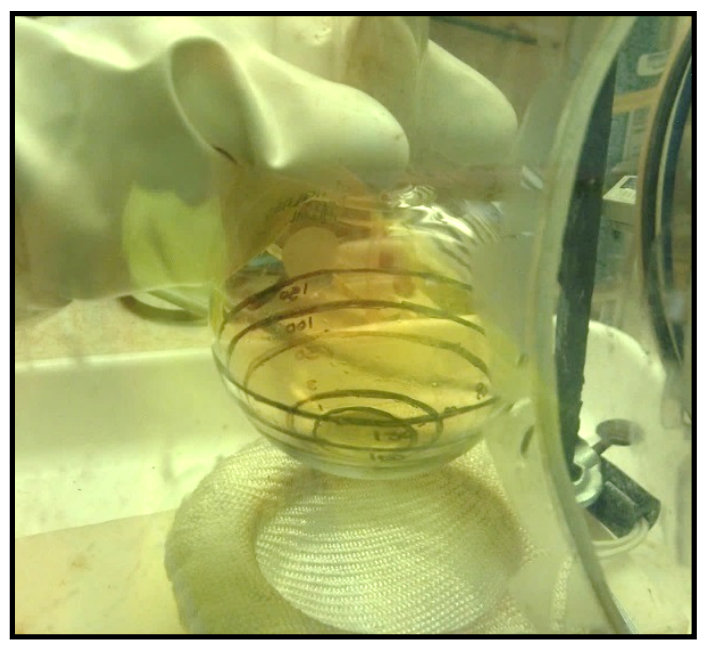

Figure 3. Boiling flask with $\mathrm{NO}_{2}$ fumes and ${ }^{249} \mathrm{Bk}$ solution.

\subsubsection{Initial Cation-Exchange Cleanup Column}

An initial cation-exchange column is used to separate ${ }^{249} \mathrm{Bk}$ and residual ${ }^{252} \mathrm{Cf}$ from other cations present in the solution (Figure 5). A $150 \mathrm{~mL}$ pear-shaped reservoir column is loaded with a $3.0 \mathrm{~mL}$ bed volume of strong cation-exchange resin (either Dowex 50W-X4 [200-400] or AG50W-X4 [200-400] H+ cationexchange resin). The glass tube containing the cation-exchange resin is $6 \mathrm{~mm}$ in diameter (inner). The resin is preconditioned with $6 \mathrm{M} \mathrm{HCl}$ and deionized ultra-pure water, and $0.1 \mathrm{M} \mathrm{of} \mathrm{HCl}$ is used to condition the column just before loading the feed solution. In separations with ${ }^{249} \mathrm{Bk}$ using Dowex resins, previous campaigns identified a green band on the column resin as a visual indicator of ${ }^{249} \mathrm{Bk}$ product elution, due to the large quantity of ${ }^{249} \mathrm{Bk}$ on the column. A schematic of the initial cation-exchange cleanup column is displayed in Figure 5.

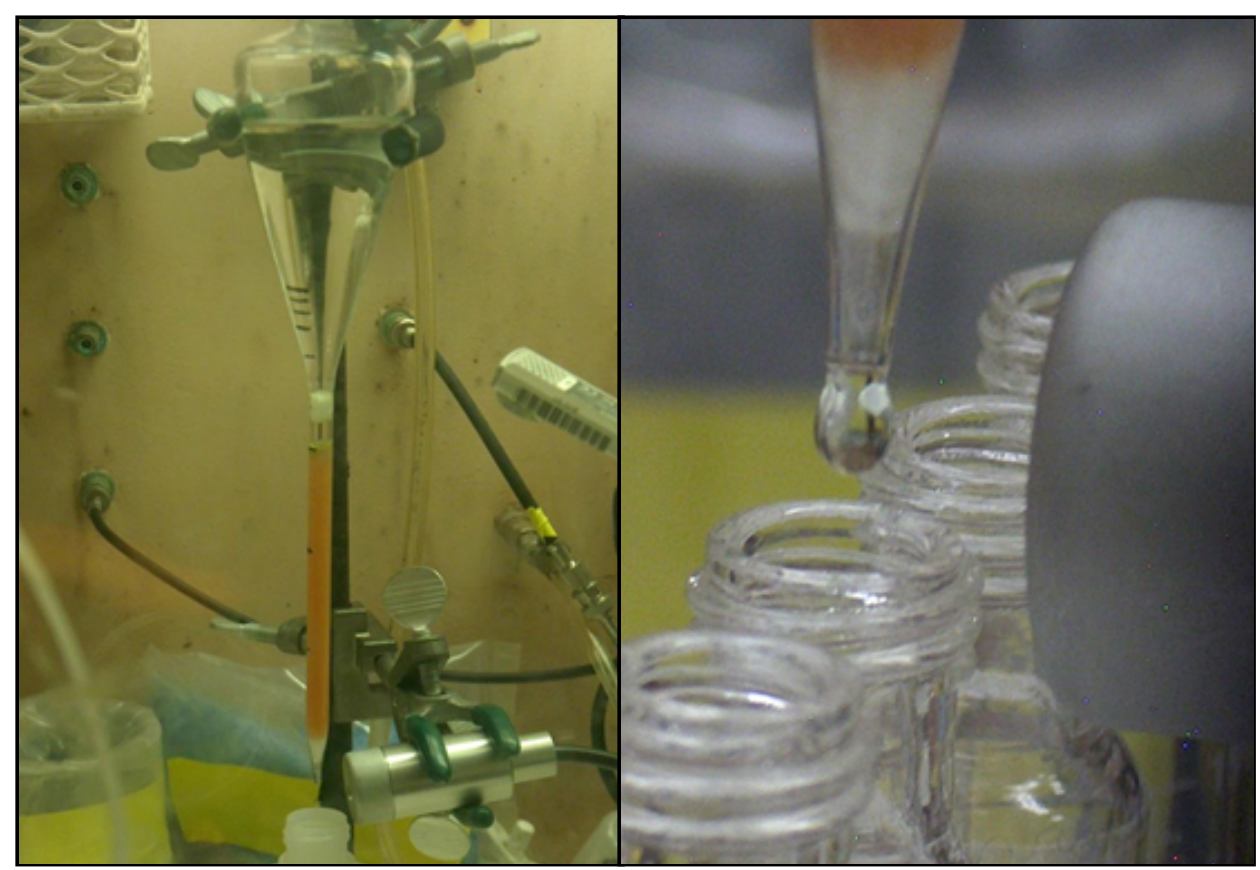

Figure 4. Initial cation-exchange cleanup column with $150 \mathrm{~mL}$ reservoir, showing elution into centrifuge tubes. 


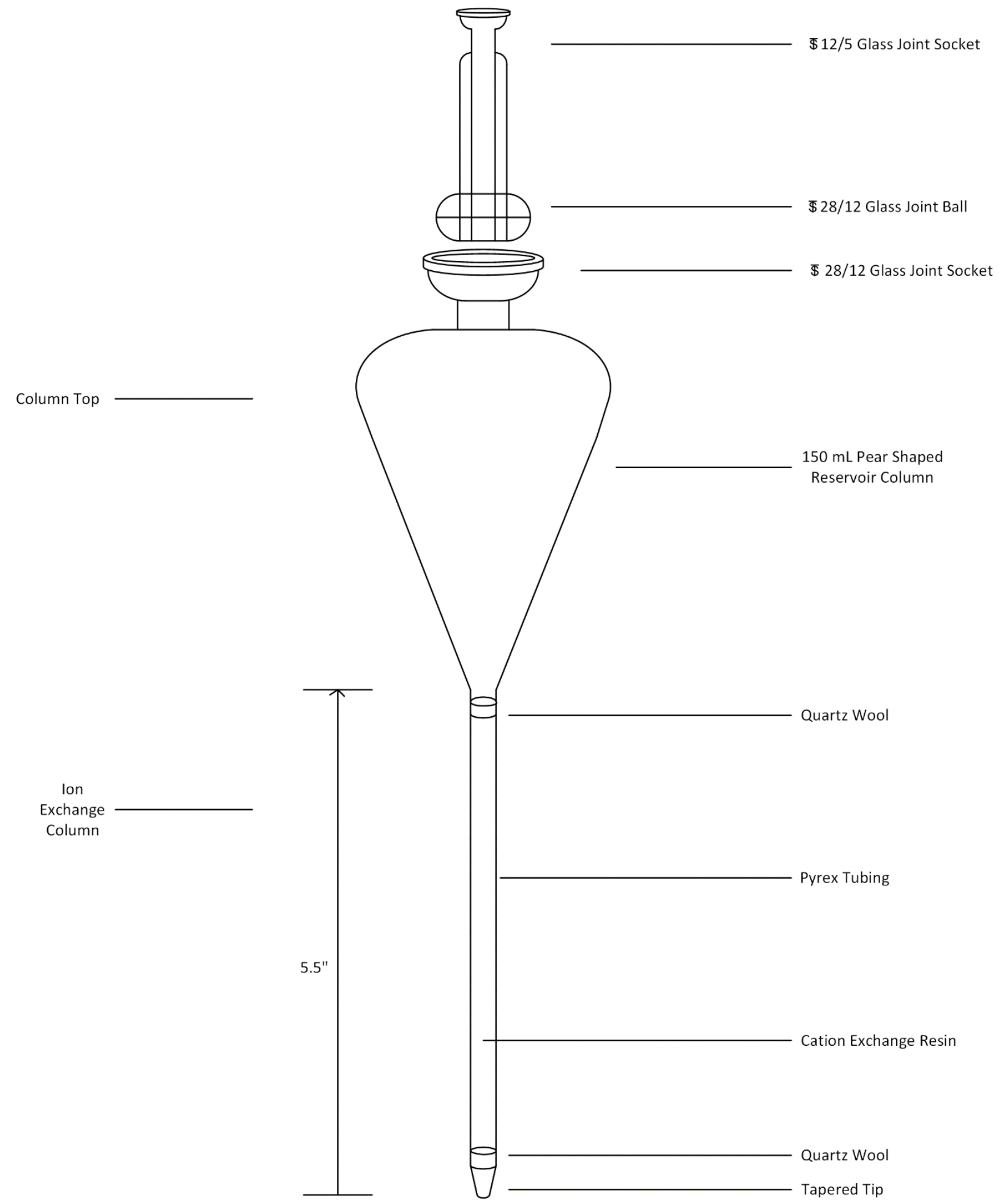

Figure 5. Initial cleanup micro-glass cation-exchange column with $150 \mathrm{~mL}$ reservoir.

The feed solution of $\sim 100 \mathrm{~mL}$ is loaded onto the column in two different fractions along with two washes of the round bottom flask and load bottle with $0.1 \mathrm{MHNO}_{3}$. This is pressurized through the column at a rate of 2 seconds per drop using argon gas. The green band is identified at the top portion of the column resin, and the eluent is collected in a polyethylene bottle. Once the load is pressurized through the column, 
five to nine bed volumes of $0.1 \mathrm{M} \mathrm{HCl}$ are added to the reservoir, followed by one to three bed volumes of $2 \mathrm{M} \mathrm{HCl}$ to strip any impurities (e.g. iron) from the column resin. The green band will move slowly down the resin in the $2 \mathrm{M} \mathrm{HCl}$, so it is important to note that if too much $2 \mathrm{M} \mathrm{HCl}$ is used, the ${ }^{249} \mathrm{Bk}$ material will elute prematurely. An additional two to five bed volumes of $6 \mathrm{M} \mathrm{HCl}$ is added to the reservoir to strip the resin, and the green band of ${ }^{249} \mathrm{Bk}$ and ${ }^{252} \mathrm{Cf}$ moves down the column. An alpha detector is used to detect ${ }^{252} \mathrm{Cf}$, and the green band is used as a visual indicator. The ${ }^{249} \mathrm{Bk},{ }^{252} \mathrm{Cf}$, and any remaining $\mathrm{M}^{3+}$ cations in the eluent are collected using centrifuge tubes (Figure 6). The berkelium and californium are collected in one centrifuge tube. The column is then rinsed with deionized water, and the centrifuge tube containing the ${ }^{249} \mathrm{Bk}$ and ${ }^{252} \mathrm{Cf}$ is placed in the evaporation unit with an infrared heat lamp and argon gas flow and reduced to less than $1 \mathrm{~mL}$ volume.

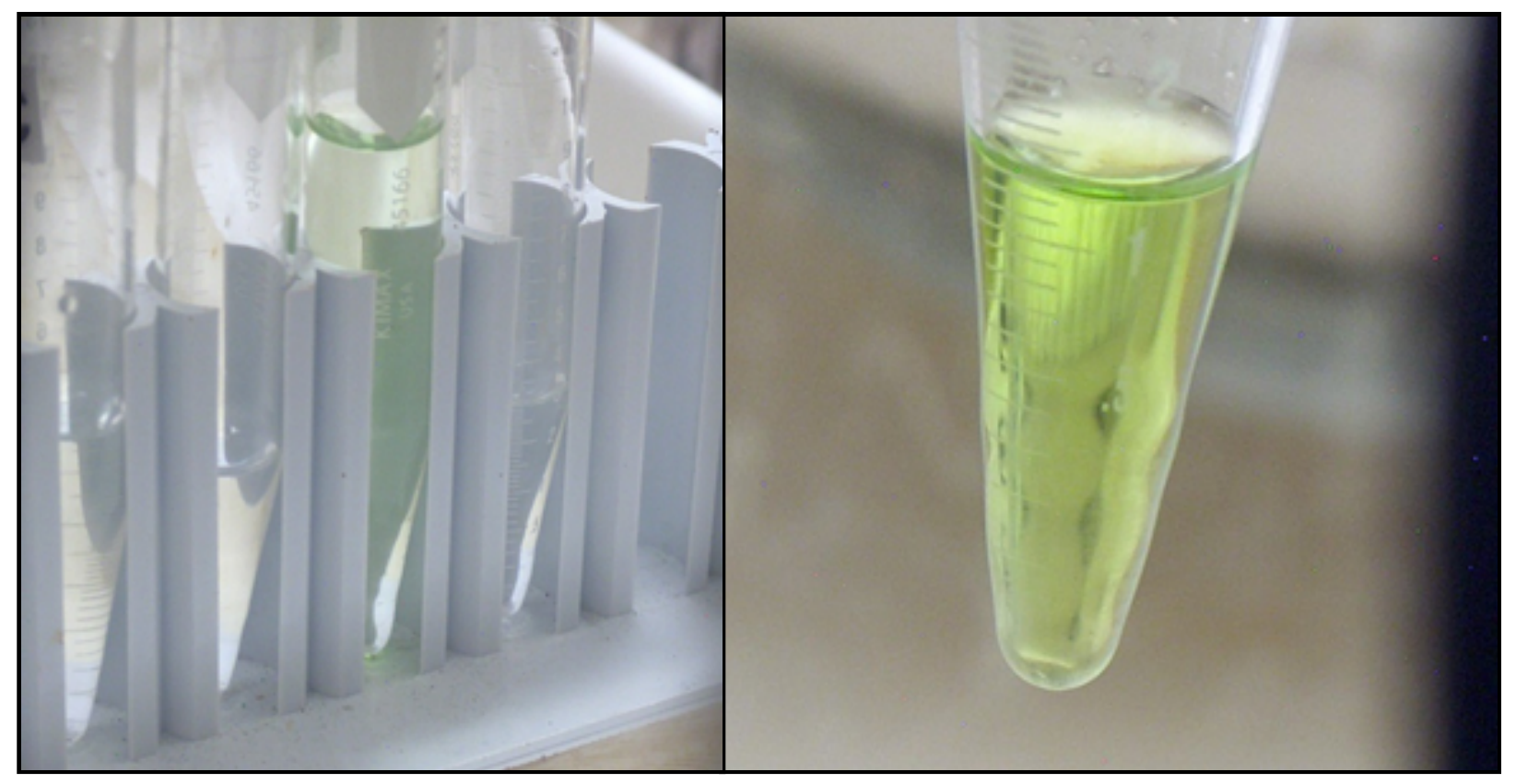

Figure 6. The ${ }^{249} B k$ product with "Bk green" color in centrifuge tube, before and after volume reduction.

\subsubsection{AHIB Cation-Exchange Column}

Next, an AHIB cation-exchange column is used to separate the ${ }^{249} \mathrm{Bk}$ product from the residual ${ }^{252} \mathrm{Cf}$. The AHIB column consists of a micro-glass, water-jacketed column with a $0.6 \mathrm{~cm}$ inner diameter and a $3.2 \mathrm{~mL}$ bed volume of strong cation-exchange resin (either Dowex 50W-X8 [200-400] or AG50W-X8 [200-400] $\mathrm{H}^{+}$cation-exchange resin). The bed volume and column size may vary based on the total mass of the isotope. A schematic of the experimental setup is displayed in Figure 7. Before use, the cation-exchange resin is preconditioned with $6 \mathrm{M} \mathrm{HCl}$ and deionized ultra-pure water. The water circulating through the water jacket is kept at a constant $73^{\circ} \mathrm{C}$. Elevated temperatures are necessary when using highly cross-linked resins to reach a resin-solution equilibrium [6]. 
Ion

Exchange

Column

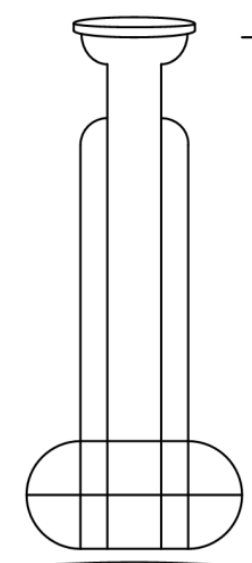

12/5 Glass Joint Socket

\$28/12 Glass Joint Ball
\$28/12 Glass Joint Socket

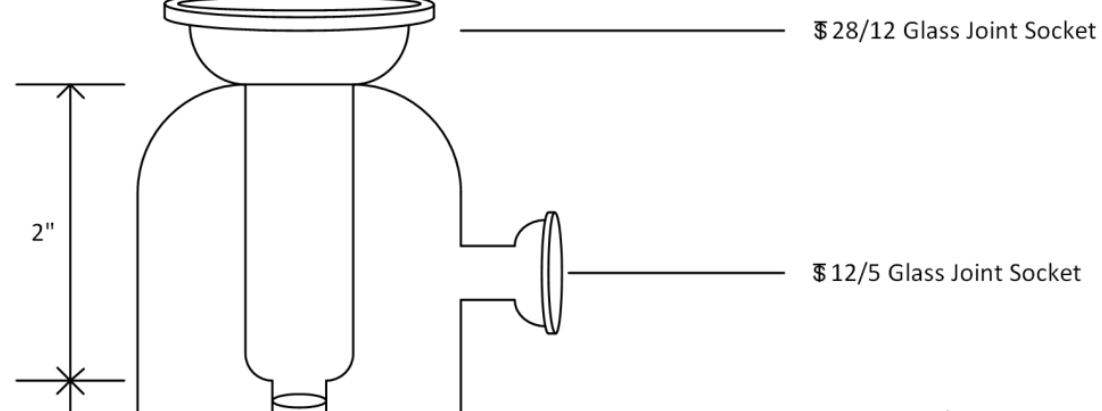

Quartz Wool

Pyrex Tubing

4-10 mm OD - $1 \mathrm{~mm}$ Wall Thickness

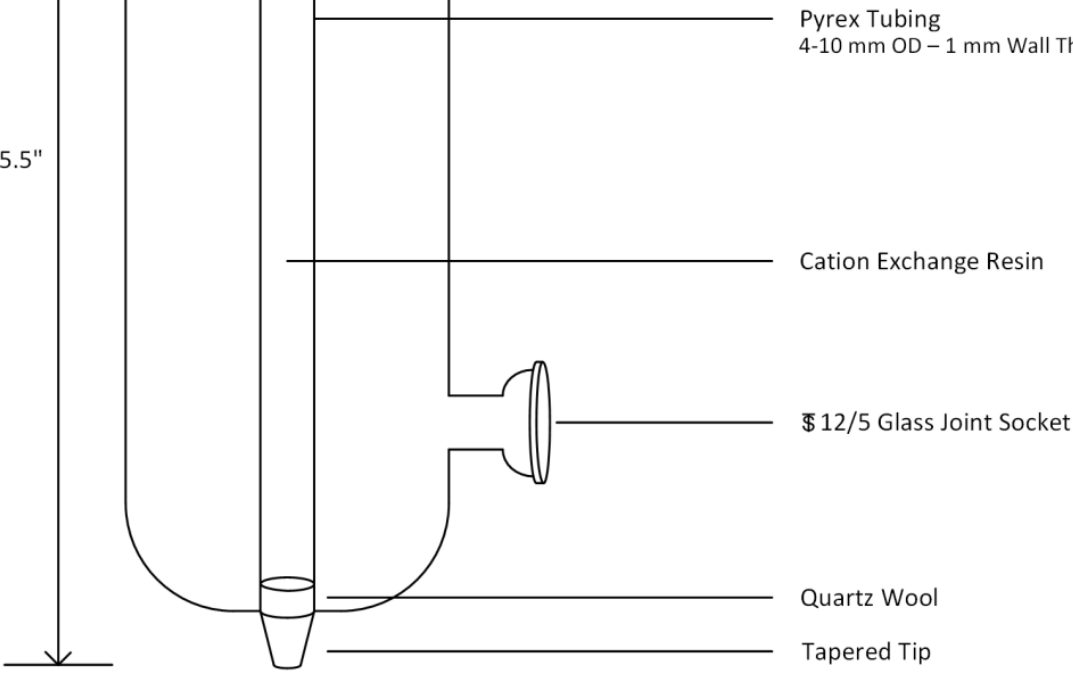

Figure 7. Micro-glass jacketed AHIB cation-exchange column.

The condensed $6 \mathrm{M} \mathrm{HCl} \mathrm{Cf-Bk}$ solution from the initial cation-exchange column is diluted to $0.2 \mathrm{M}$ with ultra-pure water as load solution for the AHIB column. The total volume of the feed solution is around $15 \mathrm{~mL}$. Following the feed solution, two bed volumes of $0.1 \mathrm{M} \mathrm{HCl}$ acid are pressurized through the column with argon gas at a rate of 2 seconds per drop. Once the feed solution and acid rinses are pressurized through the system, two bed volumes of ultra-pure water are added to flush the acid off the column. It is then 
necessary to convert the resin from an $\mathrm{H}^{+}$form to an $\mathrm{NH}_{4}{ }^{+}$form, which will allow the column to be closer to a neutral $\mathrm{pH}$. This is done by pressurizing approximately 10 bed volumes of $0.3 M \mathrm{NH}_{4} \mathrm{NO}_{3}$ through the column at the same flow rate. The $\mathrm{pH}$ is monitored throughout this process by using litmus $\mathrm{pH}$ paper to test the elution droplets. The litmus paper should not change color or should be a slight yellow or green. If the litmus paper turns red, the resin is still acidic, and additional $0.3 M \mathrm{NH}_{4} \mathrm{NO}_{3}$ should be added as needed until the resin is fully converted. The resin is then rinsed with two bed volumes of ultra-pure water to remove excess nitrate after neutrality is reached. The rinses are collected respectively in polyethylene feed, load, and raffinate bottles.

The ${ }^{249} \mathrm{Bk}$ and ${ }^{252} \mathrm{Cf}$ separation process is now initiated by loading $2-5 \mathrm{~mL}$ aliquots of $0.25 \mathrm{M}$ AHIB at a $\mathrm{pH}$ of 4.2 onto the column, pressurized by argon gas at a rate of 3.5-4 seconds per drop. The $0.25 \mathrm{M}$ AHIB at a $\mathrm{pH}$ of 4.2 elutes the $\mathrm{Cf}$ from the column. The green band begins to move down the column resin, and the raffinate bottle is replaced with centrifuge tubes to collect the eluent in separate fractions (Figure 8). Once approximately five bed volumes of $0.25 \mathrm{M}$ AHIB at a $\mathrm{pH}$ of 4.2 is run through the column and the green band reaches the bottom of the column resin, the reservoir is filled with 0.25 M AHIB at a pH of 4.6. This elutes the remaining $\mathrm{Cf}$ from the column and then elutes the ${ }^{249} \mathrm{Bk}$. After the entire eluent is collected, the column is stripped with three bed volumes of $0.5 \mathrm{M}$ AHIB at a $\mathrm{pH}$ of 4.8 , followed by three bed volumes of ultra-pure water to re-expand the resin. The fractions collected are dose rated (method for obtaining dose rates are described in Section 4) with gamma and neutron detectors. The initial dose rates are determined, and samples of each centrifuge tube are diluted and sent to be analyzed.

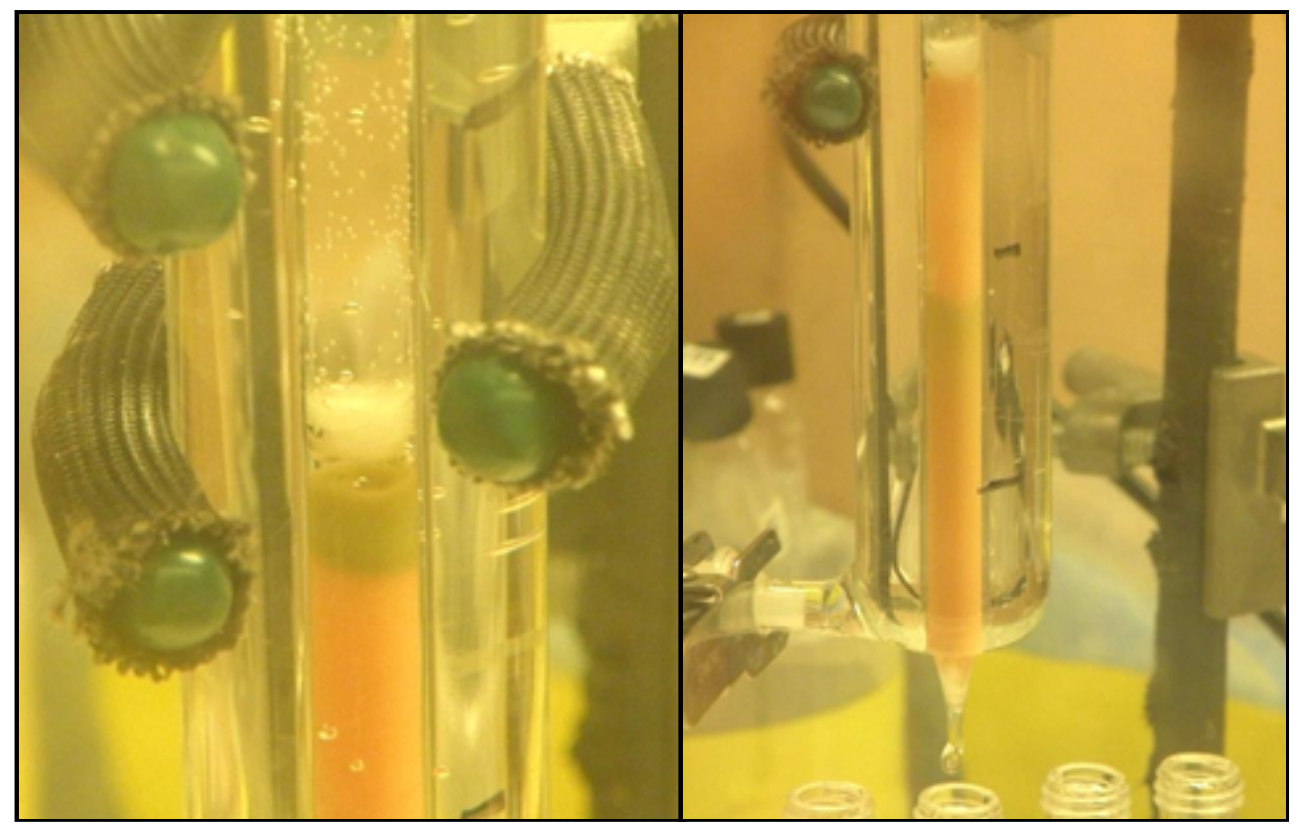

Figure 8. AHIB column loaded with ${ }^{249}$ Bk solution, showing movement of green band.

\subsubsection{Final Cation-Exchange Cleanup Column}

The purpose of the final cation-exchange cleanup column, displayed in Figure 9, is to separate the AHIB from the ${ }^{249} \mathrm{Bk}$ product. Once the analysis on the separate centrifuge tubes from the AHIB column is complete, the centrifuge tubes are combined based on the quantity of ${ }^{249} \mathrm{Bk}$ and ${ }^{252} \mathrm{Cf}$ in each centrifuge tube. The acidity concentration is adjusted to $0.2 \mathrm{M}$ with $6 \mathrm{M} \mathrm{HCl}$, and the feed solution is loaded onto a preconditioned cation-exchange column. The final cation-exchange column is identical to the initial cleanup column, consisting of a $10 \mathrm{~mL}$ reservoir micro-glass column filled with a $3.0 \mathrm{~mL}$ bed volume of strong cation-exchange resin (either Dowex 50W-X4 [200-400] or AG50W-X4 [200-400] $\mathrm{H}^{+}$cation-exchange 
resin). The reservoir is rinsed with two bed volumes of $0.1 \mathrm{M} \mathrm{HCl}$ after the feed solution is loaded, and the eluent is collected in a polyethylene raffinate bottle. After the initial rinse, five bed volumes of $0.1 \mathrm{M} \mathrm{HCl}$ is pressurized through the column at a rate of 3 seconds per drop. To initiate the stripping, three bed volumes of $2 \mathrm{M} \mathrm{HCl}$ is added to the reservoir, and the elution rate is slowed to 4 seconds per drop. The green band will start to move slowly down the column in $2 \mathrm{M} \mathrm{HCl}$, and like the initial cation-exchange column, material will prematurely elute if too much $2 \mathrm{M} \mathrm{HCl}$ is added (Figure 10). Before the green band reaches the bottom of the column, the reservoir is filled with $6 \mathrm{M} \mathrm{HCl}$ to strip the column. The green band should no longer be visible. The column is rinsed with an additional volume of $6 \mathrm{M} \mathrm{HCl}$ and ultra-pure water. Analytical samples of the centrifuge tubes are prepared. The centrifuge tubes containing the ${ }^{249} \mathrm{Bk}$ are evaporated using a heating lamp and converted to a nitric salt. Once the material volume is known, the ${ }^{249} \mathrm{Bk}$ product is prepared and dispensed based upon each campaign's customer specifications. 
Ion

Exchange

Column

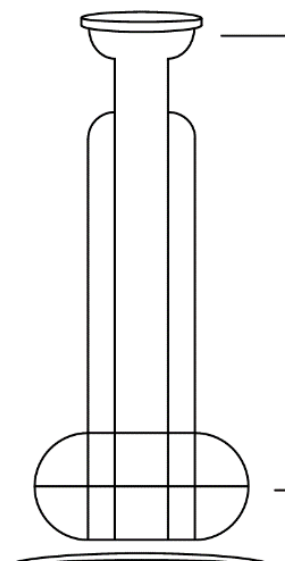

$\$ 12 / 5$ Glass Joint Socket

\$28/12 Glass Joint Ball

\$28/12 Glass Joint Socket

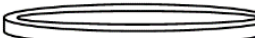

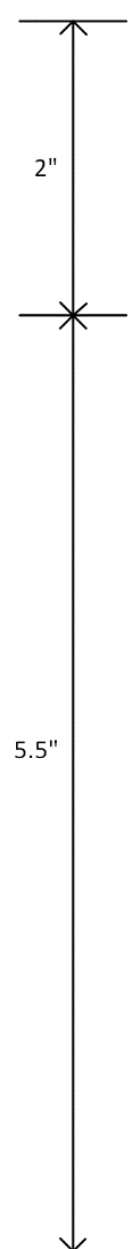

Quartz Wool

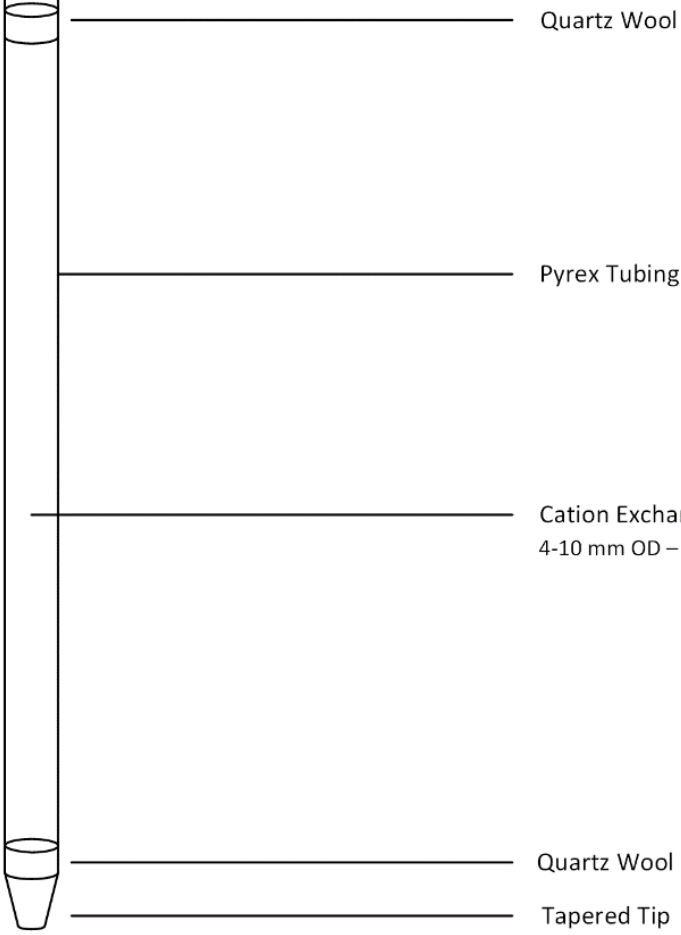

Figure 9. Final cleanup micro-glass cation-exchange column. 


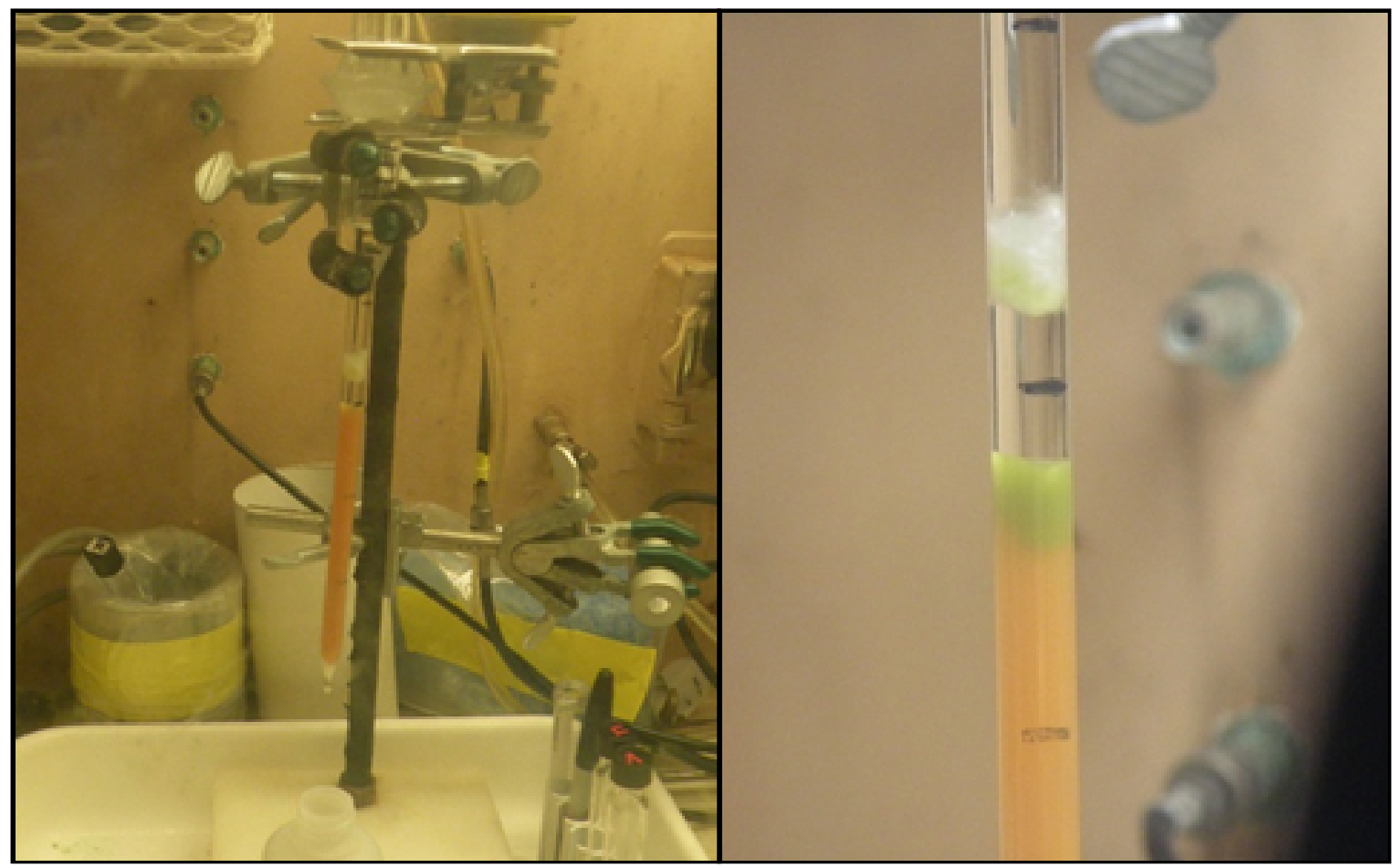

Figure 10. Final cation-exchange cleanup column with ${ }^{249}$ Bk solution loaded onto resin.

\subsection{OVERVIEW OF ${ }^{254}$ Es FINAL PURIFICATION PROCEDURES}

All experimental work and processing steps for ${ }^{254}$ Es are conducted in REDC at ORNL in Oak Ridge, Tennessee. The procedures listed below outline the processes performed for the final purification efforts of ${ }^{254} \mathrm{Es}$ in the ${ }^{252} \mathrm{Cf}$ Production C77. Mixed curium targets are irradiated in HFIR primarily for Cf production but also to produce other isotopes such as ${ }^{254} \mathrm{Es}$. The ${ }^{254} \mathrm{Es}$ material produced from the irradiation can be separated and purified for use in einsteinium characterization and heavy-isotope production studies. Once the targets are irradiated, the $\mathrm{Cm}$ targets are transferred into the REDC hot cells for dissolution and separation of actinide elements. A series of processing steps - such as the Cleanex batch solvent extraction process, $\mathrm{LiCl}$ anion exchange, $\mathrm{LiOH}$ precipitation, and $\mathrm{AHIB}$ column separation-separates the ${ }^{252} \mathrm{Cf}$ product and the $\mathrm{Cm}$ target material, making it possible to isolate the ${ }^{254} \mathrm{Es}$ material. Once the bulk of the $\mathrm{Cf}$ and $\mathrm{Cm}$ are separated, the ${ }^{254} \mathrm{Es}$ fraction is transferred to a glovebox for further processing. The following procedures are intended for separating microgram quantities of ${ }^{254} \mathrm{Es}$.

\subsubsection{Initial Cation-Exchange Concentrator Column}

An initial cation-exchange concentrator column is used to separate ${ }^{254}$ Es from other cations present in the solution from the hot cell separation steps and to concentrate the ${ }^{254} \mathrm{Es}$ into a smaller volume. A $250 \mathrm{~mL}$ pear-shaped reservoir column, similar to the pear-shaped reservoir column in Figure 5, is loaded with a $3.0 \mathrm{~mL}$ bed volume of strong cation-exchange resin (either Dowex 50W-X4 [200-400] or AG50W-X4 [200-400] $\mathrm{H}^{+}$cation-exchange resin). The glass tube containing the cation-exchange resin has a $6 \mathrm{~mm}$ inner diameter and an $8 \mathrm{~mm}$ outer diameter. The cation-exchange resin is preconditioned with $6 \mathrm{M} \mathrm{HCl}, 0.1 \mathrm{M}$ $\mathrm{HNO}_{3}$, and deionized ultra-pure water. The feed solution is loaded onto the column in several increments, making sure to only transfer enough to fill the reservoir by a fourth of the total volume in case of mishaps during transferals. The loading solution is pressurized through the column at a rate of 2 seconds per drop, eluting into a feed, load, and raffinate bottle. After transferring all of the ${ }^{254}$ Es solution, the empty transfer bottle is rinsed with $10 \mathrm{~mL}$ of $0.1 \mathrm{M} \mathrm{HCl}$ and $10 \mathrm{~mL}$ of $0.25 \mathrm{M} \mathrm{HCl}$. These rinses are added to the column, 
and the reservoir is rinsed with a final $10 \mathrm{~mL}$ of $0.25 \mathrm{M} \mathrm{HCl}$. Once the acid rinses are pressurized through the column, two bed volumes of $2 \mathrm{M} \mathrm{HCl}$ are added to the column to rinse the column. After the eluent is collected in a centrifuge tube, three bed volumes of $6 \mathrm{M} \mathrm{HCl}$ are pressurized through the column to strip the ${ }^{254} \mathrm{Es}$ product and are collected in a separate centrifuge tube. The centrifuge tube containing the ${ }^{254} \mathrm{Es}$ product has a green tint, shown in Figure 11. The column is then rinsed with water.

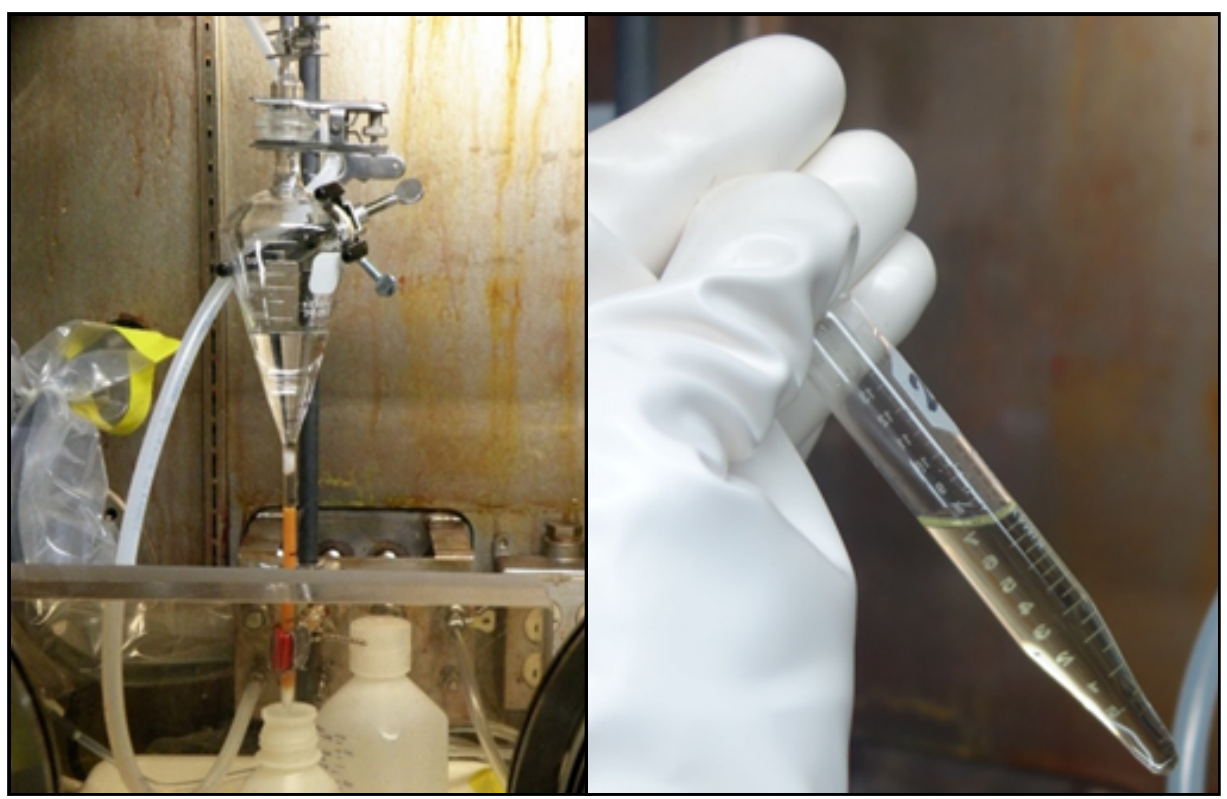

Figure 11. Initial cation-exchange concentrator column with ${ }^{254}$ Es product in a centrifuge tube after a column run.

\subsubsection{AHIB Cation-Exchange Column}

An AHIB cation-exchange column is used to separate the ${ }^{254} \mathrm{Es}$ product from residual ${ }^{252} \mathrm{Cf}$ (Figure 12). The AHIB column consists of a micro-glass, water-jacketed column with a $1.5 \mathrm{~mL}$ bed volume of strong cationexchange resin (either Dowex 50W-X8 [200-400] or AG50W-X8 [200-400] H $\mathrm{H}^{+}$cation-exchange resin). When working with microgram quantities of ${ }^{254} \mathrm{Es}$, note the outer diameter of the column needs to be $6 \mathrm{~mm}$ and the inner diameter $4 \mathrm{~mm}$ because having a larger column diameter can cause the ${ }^{254}$ Es product and residual ${ }^{252} \mathrm{Cf}$ to elute simultaneously. Figure 7 provides a schematic of the experimental setup. Before use, the cation-exchange resin is preconditioned with $6 \mathrm{M} \mathrm{HCl}$ and deionized ultra-pure water. The water circulating through the water jacket is kept at a constant $68^{\circ} \mathrm{C}$. 


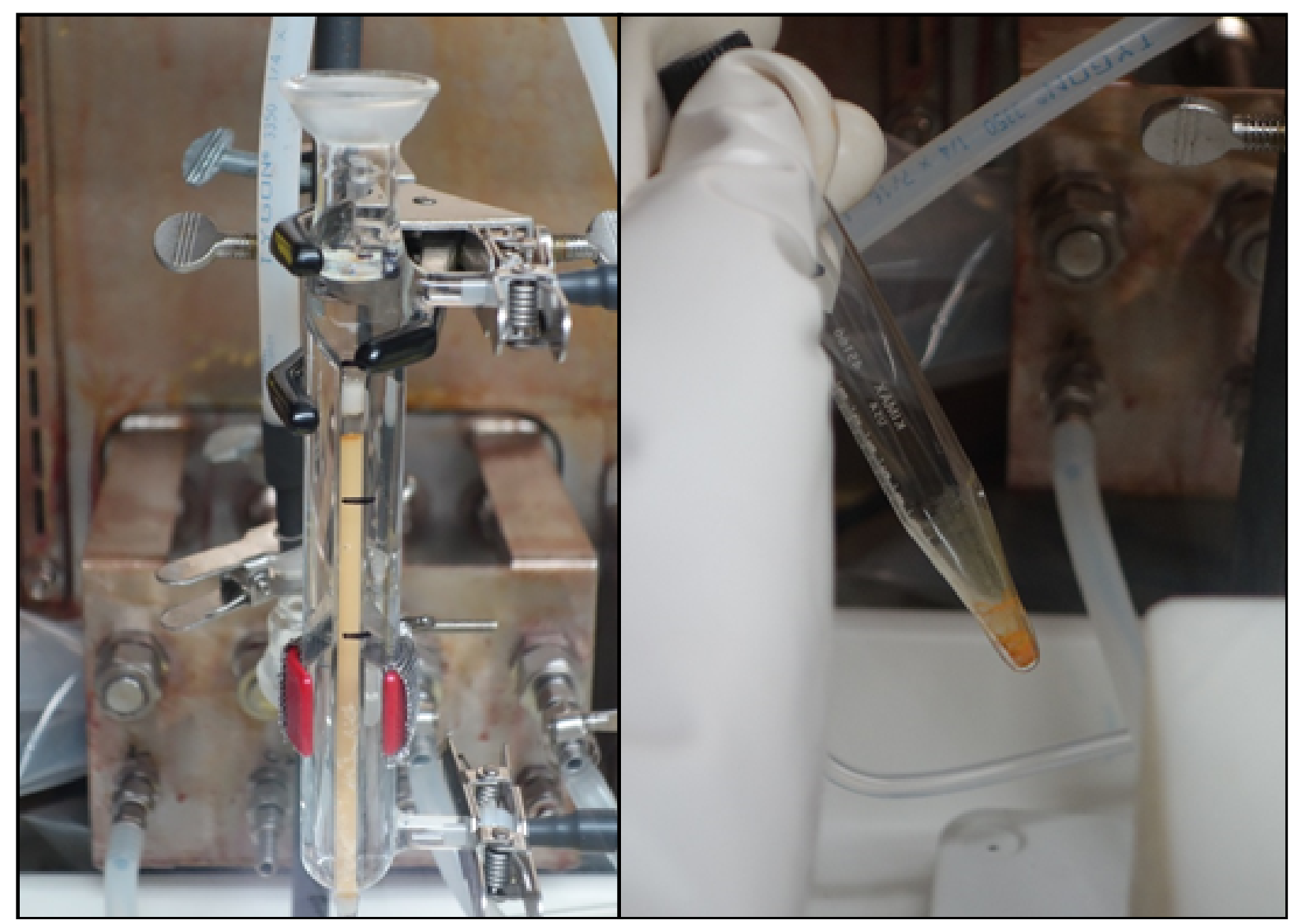

Figure 12. AHIB column loaded with ${ }^{254}$ Es solution and the centrifuge containing the product.

The product solution from the initial cation-exchange column is diluted or concentrated to $\sim 0.3 \mathrm{M} \mathrm{HCl}$ for the AHIB column. The feed solution is loaded onto the AHIB column and collected in feed, load, and raffinate bottles. Following the feed solution, the empty product solution bottle is rinsed with $0.25 \mathrm{M} \mathrm{HCl}$ and pressurized through the column with argon gas at a rate of 2 seconds per drop. Once the feed solution and acid rinses are pressurized through the system, ultra-pure water is added to relax the column resin. Then, the resin from an $\mathrm{H}^{+}$form must be converted to an $\mathrm{NH}_{4}{ }^{+}$form, which allows the column to be closer to a neutral $\mathrm{pH}$. This is done by pressurizing around 10 bed volumes of $0.3 \mathrm{MNH}_{4} \mathrm{NO}_{3}$ through the column at the same flow rate. The $\mathrm{pH}$ is monitored throughout this process using $\mathrm{pH}$ paper to test the elution droplets. The resin is then rinsed with ultra-pure water to remove excess nitrates after neutrality is reached. The rinses and conversion solution are collected in a separate $60 \mathrm{~mL}$ poly bottle.

The ${ }^{254} \mathrm{Es}$ and ${ }^{252} \mathrm{Cf}$ eluting process is now initiated by loading $0.25 \mathrm{M}$ AHIB at a $\mathrm{pH}$ of 3.8 onto the column and pressurized by argon gas at a rate of 3.5-4 seconds per drop. The $60 \mathrm{~mL}$ poly raffinate bottle is replaced with centrifuge tubes to collect the eluent in separate fractions. Around eight bed volumes of eluent are collected in the first centrifuge tube, and three bed volumes of eluent are collected in the second. After, the remainder of the $0.25 \mathrm{M}$ AHIB solution at a $\mathrm{pH}$ of 3.8 in the reservoir is collected in $2 \mathrm{~mL}$ increments until the column is stripped. After the entire eluent is collected, the column is stripped with five bed volumes of $0.5 \mathrm{M}$ AHIB at a $\mathrm{pH}$ of 4.8 along with five bed volumes of ultra-pure water to relax the column resin. The fractions collected are dose rated with gamma and neutron detectors. Once initial dose rates are determined, samples of each centrifuge tube are diluted and analyzed. 


\subsubsection{Final Cation-Exchange Cleanup Column}

The purpose of the final cation-exchange cleanup column is to separate the AHIB from the ${ }^{254}$ Es product. The separate centrifuge tubes containing any ${ }^{254} \mathrm{Es}$ are consolidated, and the acidity concentration is adjusted to $\sim 0.2 \mathrm{M}$ with $1.0 \mathrm{M} \mathrm{HCl}$. The final cation-exchange column is similar to the initial cationexchange column for ${ }^{254} \mathrm{Es}$, except the column consists of a $10 \mathrm{~mL}$ reservoir micro-glass column filled with a $1.5 \mathrm{~mL}$ bed volume of strong cation-exchange resin (either Dowex 50W-X4 [200-400] or AG50W-X4 [200-400] $\mathrm{H}^{+}$cation-exchange resin). The inner diameter of the column is $4 \mathrm{~mm}$, and the outer diameter of the column is $6 \mathrm{~mm}$. Once the feed solution is loaded onto the column, two bed volume rinses of $0.1 \mathrm{M} \mathrm{HCl}$ are used to rinse the centrifuge tubes and are added onto the column. The eluent is collected in a polyethylene raffinate bottle. After the initial rinse, eight bed volumes of $0.1 \mathrm{MHCl}$ are pressurized through the column at a rate of 4 seconds per drop. To initiate stripping, five bed volumes of $2 \mathrm{M} \mathrm{HCl}$ are added to the reservoir and pressurized through the column as well. Different centrifuge tubes were used for each collection of acid with different concentrations. The column is rinsed with three bed volumes of $6 \mathrm{M} \mathrm{HCl}$ and ultra-pure water, and analytical samples of the centrifuge tubes are prepared. The centrifuge tube containing the ${ }^{254} \mathrm{Es}$ product was brought to dryness and allowed to cool. Three drops of hydrogen peroxide are added to the dried product to remove any organic material that could have co-eluted with the product. The hydrogen peroxide is evaporated, noting any bubbling during the process. Once the material is evaporated, the ${ }^{254}$ Es product is prepared based upon customer specifications. 


\section{PRODUCTION CAMPAIGNS}

\subsection{PRODUCTION CAMPAIGN 74 (C74)}

Seven full-length, mixed-curium targets were irradiated for ${ }^{252} \mathrm{Cf}$ production in HFIR for 11 cycles, approximately 250 days of irradiation, and were discharged on December 5, 2008, with a goal of recovering $20 \mathrm{mg}$ of ${ }^{249} \mathrm{Bk}$. After 10 weeks allotted for cooling in the reactor pool, the targets were transferred back to the REDC hot cells on February 17, 2009, in time for C74 chemical processing to start on March 9, 2009. Table 2 displays the calculated contents of the irradiated target material for $\mathrm{C} 74$ before hot cell processing. An ORNL developed code called "TCOMP," which stands for "target compositions," was used in the programming language Fortran 77 to calculate the expected starting feed material after the irradiation.

Table 2. Calculated feed material for C74

\begin{tabular}{c|c|c|c|c|c|c|c|c}
\hline Item & $\begin{array}{c}{ }^{\mathbf{1 3 1}} \mathbf{I}, \\
\mathbf{C i}\end{array}$ & $\begin{array}{c}{ }^{241} \mathbf{A m}, \\
\mathbf{g}\end{array}$ & $\begin{array}{c}{ }^{243} \mathbf{A m}, \\
\mathbf{g}\end{array}$ & $\begin{array}{c}\mathbf{C m}, \\
\mathbf{g}\end{array}$ & $\begin{array}{c}{ }^{244} \mathbf{C m}, \\
\mathbf{g}\end{array}$ & $\begin{array}{c}{ }^{249} \mathbf{B k}, \\
\mathbf{m g}\end{array}$ & $\begin{array}{c}{ }^{{ }^{252} \mathbf{C f},} \\
\mathbf{m g}\end{array}$ & $\begin{array}{c}{ }^{254} \mathbf{E s ,} \\
\mathbf{\mu g}\end{array}$ \\
\hline Irradiated Targets $^{\mathrm{a}}$ & $0.4^{\mathrm{b}}$ & 0 & 0.2 & 39.8 & 8.3 & 33 & 267 & 6 \\
\hline Rework & 0 & 0.8 & 2.6 & 13.1 & 3.5 & 0 & 7 & 0 \\
\hline Total & 0.4 & 0.8 & 2.8 & 52.9 & 11.8 & 33 & 274 & 6 \\
\hline
\end{tabular}

aTarget numbers S-27, S-28, S-30, S-31, S-32, S-33, and S-34.

bIncludes $0.08 \mathrm{Ci}$ accumulated from ${ }^{252} \mathrm{Cf}$ fissions plus $0.3 \mathrm{Ci}$ left from the fissions during the irradiation.

Hot cell processing began on March 9, 2009, and included dissolution of targets, Cleanex batch solvent extraction process, $\mathrm{LiCl}$ anion exchange, $\mathrm{LiOH}$ precipitation, deep bed filtration, and ion exchange using AHIB column separation to separate ${ }^{252} \mathrm{Cf}$ and other $\mathrm{Cm}$ target material before any Bk separation steps. Hot cell processing is outlined more in depth in the ORNL report "Campaign 75 - Production of Californium252 and the Recovery of Curium Feed Material at the Radiochemical Engineering Development Center" by Garrison et al. The final hot cell separation step for Bk is the Berkex batch solvent extraction process, which was performed on April 30, 2009.

After completion of the Berkex batch solvent extraction process to remove ${ }^{249} \mathrm{Bk}$ from the majority of other isotopes in the hot cells of REDC, the processed solution was sampled and bagged into a glovebox (7920211-04). The post-Berkex solution was analyzed and reported to contain $23.37 \mathrm{mg}$ of ${ }^{249} \mathrm{Bk}$ with less than $50 \mu \mathrm{g}$ of ${ }^{249} \mathrm{Cf}$ and $0.4 \mu \mathrm{g}$ of ${ }^{252} \mathrm{Cf}$. The final cleanup procedures outlined in Sections 2.1.1-2.1.5 were completed by Curtis Porter and Frank Riley for C74. The final Bk purification and dispensing began on May 29, 2009, and culminated with shipment of the final product on June 9, 2009. The process started with organic scrubbing using TCE and reduction of volume. After the volume reduction, $1.6 \mathrm{~mL}$ of concentrated nitric acid solution $(\sim 15 \mathrm{M})$ containing ${ }^{249} \mathrm{Bk}$ was dose rated using an ion chamber survey meter with a beta slide. The concentrated solution was dose rated, measuring $450 \mathrm{mR} / \mathrm{h}$ closed window (closed beta slide), and was diluted to around $120 \mathrm{~mL}$ using deionized water. The empty tube previously containing the solution of ${ }^{249} \mathrm{Bk}$ was rinsed several times and combined with the remaining diluted solution, yielding a final concentration of $0.2 \mathrm{M}$ in a total of $150 \mathrm{~mL}$ of solution. 


\section{C74 Initial Cleanup Column}

The $150 \mathrm{~mL}$ solution containing ${ }^{249} \mathrm{Bk}$ was loaded onto the initial cleanup column, displayed in Figure 5, with a $3.0 \mathrm{~mL}$ bed volume of Dowex 50W-X4 (200-400) cation-exchange resin. The column was preconditioned with $\sim 10 \mathrm{~mL}$ of $0.1 \mathrm{M} \mathrm{HCl}$. The purpose of the initial cleanup column is to remove any impurities, such as group one, group two, and some transition metals (e.g. iron), from the berkelium/californium material present in the solution from previous hot cell operations. From the column, $8.1 \mathrm{~mL}$ of product was collected in a single centrifuge tube with contact gamma dose readings of $550 \mathrm{mR} / \mathrm{h}$ closed window, $1,100 \mathrm{mR} / \mathrm{h}$ open window, and contact neutron dose readings of $80 \mathrm{mrem} / \mathrm{h}$. The product was immediately evaporated to around $0.3 \mathrm{~mL}$ in preparation for the AHIB column, resulting in a concentration of $\sim 6 \mathrm{M} \mathrm{HCl}$.

\section{C74 AHIB Column}

The concentrated product solution from the initial cation column run was diluted to $7.2 \mathrm{~mL}$ using deionized water, resulting in a concentration of $0.2 \mathrm{M}$. The diluted solution was pressurized through an AHIB column containing a $3.2 \mathrm{~mL}$ bed volume of Dowex 50W-X8 (200-400) cation-exchange resin with a drop rate of 2 seconds per drop. Several acid rinses $(0.2 M)$ of the centrifuge tube holding the feed solution were added to the column. Eight fractions were collected, dose rated, and sampled. Table 3 displays the liquid scintillation, gamma, alpha, and neutron analysis of centrifuge tubes 1-8, and Table 4 displays the mass of ${ }^{249} \mathrm{Bk},{ }^{249} \mathrm{Cf}$, and ${ }^{252} \mathrm{Cf}$ in each centrifuge tube. Note that ${ }^{249} \mathrm{Cf}$ is the first daughter product of ${ }^{249} \mathrm{Bk}$ so its presence in the solution is expected, but its activity is used as a tracer to determine the ${ }^{252} \mathrm{Cf}$ elution pattern.

Table 3. Dose rates and volumes of centrifuge tubes 1-8 from AHIB column separation

\begin{tabular}{|c|c|c|c|c|c|c|c|c|}
\hline Item $^{a}$ & $\begin{array}{c}{ }^{249} \text { Bk Beta } \\
\text { by Liquid } \\
\text { Scintillation, } \\
\text { Bq/mL } \\
\end{array}$ & $\begin{array}{l}{ }^{249} \mathrm{Cf} \gamma \\
\mathrm{Bq} / \mathrm{mL}\end{array}$ & $\begin{array}{c}\text { Gross } \alpha \\
\text { Bq/mL }\end{array}$ & $\begin{array}{c}5.80 \\
\text { MeV } \alpha, \\
{ }^{249} \mathrm{Cf} \%\end{array}$ & $\begin{array}{c}6.11 \\
\mathrm{MeV} \alpha, \\
{ }^{252} \mathrm{Cf} \%\end{array}$ & $\begin{array}{c}\text { Gross } \\
\text { neutron, } \\
\text { cpm/mL }\end{array}$ & $\begin{array}{c}\text { Volume, } \\
\text { mL }\end{array}$ & [AHIB]/pH \\
\hline FLR $^{b}$ & $8.01 \mathrm{E}+06$ & $8.85 \mathrm{E}+02$ & $\mathrm{ND}^{\mathrm{d}}$ & ND & ND & $4.00 \mathrm{E}+03$ & 50 & ND \\
\hline CT1 & $7.68 \mathrm{E}+05$ & $4.64 \mathrm{E}+03$ & ND & ND & ND & $4.00 \mathrm{E}+03$ & 6.9 & $0.25 \mathrm{M} / 4.2$ \\
\hline CT2 & $1.65 \mathrm{E}+07$ & $1.15 \mathrm{E}+07$ & $1.40 \mathrm{E}+07$ & 86.2 & 13.8 & $9.40 \mathrm{E}+05$ & 2.9 & $0.25 \mathrm{M} / 4.2$ \\
\hline CT3 & $2.66 \mathrm{E}+08$ & $8.66 \mathrm{E}+06$ & $1.00 \mathrm{E}+07$ & 84.3 & 15.2 & $7.60 \mathrm{E}+05$ & 2.7 & $0.25 \mathrm{M} / 4.2$ \\
\hline CT4 & $8.07 \mathrm{E}+09$ & $1.15 \mathrm{E}+06$ & $\mathrm{ND}$ & ND & ND & $8.10 \mathrm{E}+05$ & 1.7 & $0.25 \mathrm{M} / 4.6$ \\
\hline CT5 & $3.20 \mathrm{E}+10$ & $5.00 \mathrm{E}+05$ & ND & ND & ND & $3.20 \mathrm{E}+06$ & 0.9 & $0.25 \mathrm{M} / 4.6$ \\
\hline CT6 & $1.60 \mathrm{E}+11$ & $1.55 \mathrm{E}+06$ & ND & ND & ND & $8.00 \mathrm{E}+06$ & 7.8 & $0.25 \mathrm{M} / 4.6$ \\
\hline CT7 & $4.92 \mathrm{E}+10$ & $1.10 \mathrm{E}+06$ & ND & ND & ND & $8.00 \mathrm{E}+06$ & 4.6 & $0.25 \mathrm{M} / 4.6$ \\
\hline $\mathrm{CT}^{\mathrm{c}}$ & $5.10 \mathrm{E}+07$ & $8.53 \mathrm{E}+02$ & ND & ND & ND & $4.00 \mathrm{E}+03$ & 9.7 & $0.50 \mathrm{M} / 4.8$ \\
\hline
\end{tabular}

${ }^{\mathrm{a} C e n t r i f u g e}$ tubes (CT) are listed in order of elution.

${ }^{\mathrm{b}}$ Feed/load/raffinate.

${ }^{\mathrm{c}} \mathrm{CT} 8$ also contained $1.10 \mathrm{E}+06 \mathrm{~Bq} / \mathrm{mL}$ of ${ }^{141} \mathrm{Ce}$ and $2.00 \mathrm{E}+05 \mathrm{~Bq} / \mathrm{mL}$ of ${ }^{144} \mathrm{Ce}$.

dNo data. 
Table 4. Mass of ${ }^{249} \mathrm{Bk},{ }^{249} \mathrm{Cf}$, and ${ }^{252} \mathrm{Cf}$ in centrifuge tubes 1-8

\begin{tabular}{c|c|c|c}
\hline Item & $\begin{array}{c}\text { Mass of } \\
{ }^{\mathbf{2 4 9}} \mathbf{B k}, \mathbf{m g}\end{array}$ & $\begin{array}{c}\text { Mass of } \\
{ }^{\mathbf{2 4 9}} \mathbf{C f}, \mathbf{~ m g}\end{array}$ & $\begin{array}{c}\text { Mass of } \\
\mathbf{2 5 2} \mathbf{C f}, \mathbf{m g}\end{array}$ \\
\hline FLR $^{\mathrm{a}}$ & $6.61 \mathrm{E}-03$ & $2.92 \mathrm{E}-04$ & $1.50 \mathrm{E}-05$ \\
\hline CT1 & $8.60 \mathrm{E}-05$ & $2.11 \mathrm{E}-04$ & $2.00 \mathrm{E}-06$ \\
\hline CT2 & $7.90 \mathrm{E}-04$ & $2.20 \mathrm{E}-01$ & $2.04 \mathrm{E}-04$ \\
\hline CT3 & $1.19 \mathrm{E}-02$ & $1.54 \mathrm{E}-01$ & $1.53 \mathrm{E}-04$ \\
\hline CT4 & $2.26 \mathrm{E}-01$ & $1.29 \mathrm{E}-02$ & $1.03 \mathrm{E}-04$ \\
\hline CT5 & $4.75 \mathrm{E}-01$ & $2.97 \mathrm{E}-03$ & $2.15 \mathrm{E}-04$ \\
\hline CT6 & $2.06 \mathrm{E}+01$ & $7.98 \mathrm{E}-02$ & $4.66 \mathrm{E}-03$ \\
\hline CT7 & $3.73 \mathrm{E}+00$ & $3.33 \mathrm{E}-02$ & $2.75 \mathrm{E}-03$ \\
\hline CT8 & $8.27 \mathrm{E}-03$ & $5.50 \mathrm{E}-05$ & $3.00 \mathrm{E}-06$ \\
\hline
\end{tabular}

${ }^{\mathrm{a}}$ Feed/load/raffinate.

\section{C74 Final Cleanup Column}

CT5, CT6, and CT7 were chosen for the final cleanup column, which removes any remaining AHIB reagent. These three fractions contained the majority of ${ }^{249} \mathrm{Bk}$ with small quantities of ${ }^{252} \mathrm{Cf}$. The three centrifuge tubes were combined and acidified with $0.7 \mathrm{~mL}$ of $6 \mathrm{M} \mathrm{HCl}$, resulting in a $0.3 \mathrm{M}$ solution. Once acidified, the solution was loaded onto a cation-exchange column consisting of a $3.0 \mathrm{~mL}$ bed volume of Dowex $50 \mathrm{~W}$ $\mathrm{X} 4$ (200-400) cation-exchange resin in the $\mathrm{H}^{+}$form and was pressurized through the column at a rate of 2 seconds per drop. The product was collected in a centrifuge tube with dose rates of $350 \mathrm{mR} / \mathrm{h}$ closed window and $600 \mathrm{mR} / \mathrm{h}$ open window taken with an ion chamber survey meter. A sample was pulled to be analyzed by liquid scintillation, gamma, alpha, and neutron spectroscopy. The final analysis of the sample is displayed in Table 5.

Table 5. Analysis of ${ }^{249} \mathrm{Bk}$ solution after final cleanup procedures

\begin{tabular}{c|c}
\hline Isotope & Mass, mg \\
\hline${ }^{249} \mathrm{Bk}$ & $2.22 \mathrm{E}+01$ \\
\hline${ }^{252} \mathrm{Cf}$ & $1.75 \mathrm{E}-06$ \\
\hline${ }^{249} \mathrm{Cf}$ & $5.48 \mathrm{E}-02$ \\
\hline
\end{tabular}

aFirst daughter decay ingrowth.

After analysis of the sample, the $\mathrm{HCl}$ present in the solution was evaporated to dryness using a heat lamp. An aliquot of $0.3 \mathrm{~mL}$ of ultra-pure nitric acid was added to the centrifuge tube to convert the sample from a chloride salt to a nitric salt. The nitric acid was then evaporated to dryness. The nitric salt was then dissolved in $1 \mathrm{~mL}$ of $2 \mathrm{MHNO}_{3}$ and transferred to a small acid-leached glass bottle. After the transfer, four $1 \mathrm{~mL}$ rinses of $2 \mathrm{M}$ ultra-pure $\mathrm{HNO}_{3}$ were added to the evaporation tube and then added to the glass bottle, resulting in a $5 \mathrm{~mL}$ volume. The solution was then pipetted in $1 \mathrm{~mL}$ volumes into five labeled, leached, glass-stoppered quartz cones, and each quartz cone was evaporated to dryness. Table 6 displays the dose rates for each quartz cone. 
Table 6. Dose rates and volumes of quartz cones sent to customers in Dimitrovgrad, Russia

\begin{tabular}{c|c|c|c}
\hline \multirow{2}{*}{ Item } & \multicolumn{2}{|c|}{ Dose Rate, $\mathbf{m R} / \mathbf{h}$} & \multirow{2}{*}{$\begin{array}{c}\text { Dispensed } \\
\text { Volume, } \mathbf{m L}\end{array}$} \\
\cline { 2 - 3 } & $\begin{array}{c}\text { Open Window } \\
(\boldsymbol{\beta}, \boldsymbol{\gamma})\end{array}$ & $\begin{array}{c}\text { Closed Window } \\
(\boldsymbol{\gamma})\end{array}$ & 1.0 \\
\hline $2261 \mathrm{~A}$ & 460 & 250 & 1.0 \\
\hline $2261 \mathrm{~B}$ & 460 & 250 & 1.0 \\
\hline $2261 \mathrm{C}$ & 490 & 250 & 1.0 \\
\hline $2261 \mathrm{D}$ & 490 & 260 & 1.0 \\
\hline $2261 \mathrm{E}$ & 500 & 265 & \\
\hline
\end{tabular}

The total mass of $22.22 \mathrm{mg}$ of ${ }^{249} \mathrm{Bk}$ was shipped on June 15, 2009, to customers in at the Research Institute of Atomic Reactors in Dimitrovgrad, Russia, in five lead containers for use in the discovery of tennessine. On arrival, the dissolution of the ${ }^{249} \mathrm{Bk}$ nitric salts proved to be difficult. This could possibly be attributed to the overdrying of the nitric salts and the formation of an oxide, making dissolution more difficult. Careful considerations for the drying processes of ${ }^{249} \mathrm{Bk}$ nitric salts were taken for future campaigns. The accelerator experimental targets were fabricated by depositing $\mathrm{BkO}_{2}$ onto $0.74 \mathrm{mg} / \mathrm{cm}^{2}$ thick titanium foils, through the painting of the material as an organic slurry directly onto the foil at a thickness of $0.31 \mathrm{mg} / \mathrm{cm}^{2}$. The targets were placed in a heavy-ion cyclotron at the Joint Institute for Nuclear Research in Dubna, Russia, and were bombarded with high-energy ${ }^{48} \mathrm{Ca}$ atoms to produce tennessine. Reports of this study are published by Oganessian et al (2010).

\subsection{PRODUCTION CAMPAIGN 75}

Nine full-length, mixed-curium targets were irradiated in HFIR as a part of C75. Four targets were irradiated for nine cycles starting on May 5, 2010, and five targets were irradiated for one cycle starting on August 1, 2011. The five one-cycle targets were added to $C 75$ specifically to increase the amount of ${ }^{249} \mathrm{Bk}$ production resulting in a projected recovery yield for ${ }^{249} \mathrm{Bk}$ of $20 \mathrm{mg}$. Table 7 displays calculated contents of the irradiated target material for $\mathrm{C} 75$ before hot cell processing.

Table 7. Calculated feed material for $\mathbf{C 7 5}$

\begin{tabular}{c|c|c|c|c|c|c|c|c}
\hline Item & $\begin{array}{c}{ }^{\mathbf{1 3 1}} \mathbf{I}, \\
\mathbf{C i}\end{array}$ & $\begin{array}{c}{ }^{\mathbf{2 4 1}} \mathbf{A m}, \\
\mathbf{g}\end{array}$ & $\begin{array}{c}{ }^{243} \mathbf{A m}, \\
\mathbf{G}\end{array}$ & $\begin{array}{c}\mathbf{C m}, \\
\mathbf{g}\end{array}$ & $\begin{array}{c}{ }^{244} \mathbf{C m}, \\
\mathbf{g}\end{array}$ & $\begin{array}{c}{ }^{249} \mathbf{B k}, \\
\mathbf{M g}\end{array}$ & $\begin{array}{c}{ }^{252} \mathbf{C f}, \\
\mathbf{m g}\end{array}$ & $\begin{array}{c}{ }^{254} \mathbf{E s ,} \\
\mathbf{\mu g}\end{array}$ \\
\hline Irradiated Targets $^{\mathrm{a}}$ & $0.2^{\mathrm{b}}$ & 0 & 1.3 & 48.7 & 9.7 & 35 & 167 & 3 \\
\hline Rework $^{\mathrm{c}}$ & 0 & 1.6 & 4.3 & 36.5 & 8.6 & 0 & 17 & 0 \\
\hline Total & 0.2 & 1.6 & 5.6 & 85.2 & 18.3 & 35 & 174 & 3 \\
\hline
\end{tabular}

aTarget numbers S-24, S-25, S-26, S-35, S-36, S-38, S-39, S-40, and S-41.

bincludes $0.04 \mathrm{Ci}$ accumulated from ${ }^{252} \mathrm{Cf}$ fissions plus $0.14 \mathrm{Ci}$ left from the fissions during the irradiation.

'Rework includes C74 chemical processing recycle (CY09T23CL-2), C74 oxide scrap (74CO-4), C73 target scrap (74CL-5), and C74 target scrap (S-37 plus 31 pellets).

After irradiation ending on August 26, 2011, the targets were removed from the reactor core and placed in the reactor pool to allow time for cooling. The nine targets were then transferred back to REDC on December 5, 2011, for hot cell processing. The Berkex batch solvent extraction process was performed on January 27, 2012. Analysis of the post-Berkex aqueous solution (Bk fraction) on February 2, 2012, showed $27.54 \mathrm{mg}$ of ${ }^{249} \mathrm{Bk}$ by beta spectrometry and $25.67 \mathrm{mg}$ by alpha spectrometry. Only small quantities of ${ }^{252} \mathrm{Cf}$ were detected: $65 \mathrm{ng}$ and $85 \mathrm{ng}$ by neutron and alpha spectroscopy, respectively. 
Shelley Van Cleve, Clarice Phelps, Rose Boll, and Frank Riley completed the final cleanup procedures outlined in Sections 2.1.1-2.1.5 in an REDC glovebox (7920-211-04). Final processing started on February 3,2012 , with the TCE scrubbing and volume reduction. After the volume reduction, the solution containing ${ }^{249} \mathrm{Bk}$ was transferred to a $15 \mathrm{~mL}$ glass centrifuge tube labeled "Centrifuge Tube 1," and the rinse of the boiling flask was transferred to a separate centrifuge tube labeled "Centrifuge Tube 2." Approximate dose readings were taken using an ion chamber survey meter with a beta slide (Table 8).

Table 8. Dose rates and volume of centrifuge tubes 1 and 2 after volume reduction

\begin{tabular}{c|c|c|c}
\hline \multirow{2}{*}{ Item } & \multicolumn{2}{|c|}{ Dose Rate, $\mathbf{m R} / \mathbf{h}$} & \multirow{2}{*}{ Volume, $\mathbf{m L}$} \\
\cline { 2 - 3 } & $\begin{array}{c}\text { Open Window } \\
(\boldsymbol{\beta}, \boldsymbol{\gamma})\end{array}$ & $\begin{array}{c}\text { Closed Window } \\
(\boldsymbol{\gamma})\end{array}$ & \\
\hline CT1 & 1500 & 425 & 6.2 \\
\hline CT2 & 88 & 2 & 5 \\
\hline
\end{tabular}

\section{C75 Initial Cleanup Column}

The contents of the first two centrifuge tubes (CT), CT1 and CT2, were transferred to a polyethylene bottle and diluted to $0.2 \mathrm{M}$ with ultra-pure water to be loaded onto the initial cleanup column, resulting in a volume of around $90 \mathrm{~mL}$. The column consisted of a $3.0 \mathrm{~mL}$ bed volume of Dowex 50W-X4 (200-400) cationexchange resin, prewashed with $6 \mathrm{M} \mathrm{HCl}$ and ultra-pure distilled water. After following the procedures listed in Section 2.1.3 and after several acid rinses, centrifuge tubes 3, 4, 5, and 6 were collected from the initial cleanup column and were dose rated (Table 9).

Table 9. Dose rates and volumes of centrifuge tubes 3-6 after initial cleanup column

\begin{tabular}{c|c|c|c}
\hline \multirow{2}{*}{ Item } & \multicolumn{2}{|c|}{ Dose Rate, $\mathbf{m R} / \mathbf{h}$} & \multirow{2}{*}{ Volume, $\mathbf{~} \mathbf{L}$} \\
\cline { 2 - 3 } & $\begin{array}{c}\text { Open Window } \\
(\boldsymbol{\beta}, \boldsymbol{\gamma})\end{array}$ & $\begin{array}{c}\text { Closed Window } \\
(\boldsymbol{\gamma})\end{array}$ & 150 \\
\hline FLR $^{\mathrm{a}}$ & background & 1 & 4.6 \\
\hline CT3 & background & background & 2.8 \\
\hline CT4 & background & background & 10 \\
\hline CT5 & 1,200 & 290 & 2.7 \\
\hline CT6 & background & background & \\
\hline
\end{tabular}

${ }^{\mathrm{a}} \mathrm{Feed} / \mathrm{load} / \mathrm{raffinate}$.

\section{C75 AHIB Column}

After determining the absence of ${ }^{249} \mathrm{Bk}$ in centrifuge tubes 3, 4, and 5 with liquid scintillation analysis, CT5 was evaporated to $0.7 \mathrm{~mL}$, diluted with ultra-pure water to $15 \mathrm{~mL}$ resulting in a $0.2 \mathrm{M}$ nitric acid solution. The solution was pressurized through a $3.2 \mathrm{~mL}$ bed volume of Dowex 50W-X8 (200-400) AHIB column with a drop rate of 2 seconds per drop. The procedures listed in Section 2.1.4 were followed meticulously. Smaller volumes were collected in the following centrifuge tubes to allow complete elution of residual ${ }^{252} \mathrm{Cf}$ separated from the majority of the ${ }^{249} \mathrm{Bk}$ product. An ion chamber survey meter with a beta slide detected the eluting ${ }^{249} \mathrm{Bk}$ product, and a neutron detector was used to detect the elution of residual ${ }^{252} \mathrm{Cf}$. Liquid scintillation analysis, alpha, and neutron spectroscopy determined where the majority of the ${ }^{249} \mathrm{Bk}$ eluted and which fractions would be used in the final cleanup column. The data obtained on February 8, 2012, is found in Table 10Table 11. 
Table 10. Dose rates and volumes of centrifuge tubes 7-20 from AHIB column separation

\begin{tabular}{|c|c|c|c|c|c|c|c|}
\hline Item $^{\mathrm{a}}$ & $\begin{array}{c}{ }^{249} \text { Bk Beta } \\
\text { by Liquid } \\
\text { Scintillation, } \\
\text { Bq/mL }\end{array}$ & $\begin{array}{l}\text { Gross } \alpha, \\
\text { Bq/mL }\end{array}$ & $\begin{array}{c}5.80 \mathrm{MeV} \alpha \\
{ }^{249} \mathrm{Cf} \%\end{array}$ & $\begin{array}{l}6.11 \mathrm{MeV} \alpha \\
{ }^{252} \mathrm{Cf} \%\end{array}$ & $\begin{array}{c}\text { Gross } \\
\text { neutron } \\
\text { cpm/mL }\end{array}$ & $\begin{array}{c}\text { Volume, } \\
\text { mL }\end{array}$ & [AHIB]/pH \\
\hline FLR $^{b}$ & $3.42 \mathrm{E}+02$ & $<1.3 \mathrm{E}+01$ & $\mathrm{ND}^{\mathrm{d}}$ & ND & $<20$ & 60 & ND \\
\hline CT7 & $2.08 \mathrm{E}+03$ & $2.4 \mathrm{E}+02$ & ND & ND & $<20$ & 6.7 & $0.25 \mathrm{M} / 4.2$ \\
\hline $\mathrm{CT} 8$ & $6.94 \mathrm{E}+02$ & $1.3 \mathrm{E}+02$ & 56.4 & ND & $<20$ & 2.7 & $0.25 \mathrm{M} / 4.2$ \\
\hline СТ9 & $4.60 \mathrm{E}+03$ & $3.5 \mathrm{E}+04$ & 87.5 & 6.70 & $4.70 \mathrm{E}+02$ & 3.2 & $0.25 \mathrm{M} / 4.2$ \\
\hline CT10 & $7.90 \mathrm{E}+03$ & $6.7 \mathrm{E}+04$ & 86.6 & 6.90 & $8.60 \mathrm{E}+02$ & 1.8 & $0.25 \mathrm{M} / 4.2$ \\
\hline CT11 & $4.44 \mathrm{E}+06$ & $7.3 \mathrm{E}+04$ & 88.0 & 6.50 & $9.20 \mathrm{E}+02$ & 1.0 & $0.25 \mathrm{M} / 4.2$ \\
\hline CT12 & $6.59 \mathrm{E}+07$ & $7.1 \mathrm{E}+04$ & 86.8 & ND & $1.30 \mathrm{E}+02$ & 0.9 & $0.25 \mathrm{M} / 4.2$ \\
\hline CT13 & $2.25 \mathrm{E}+05$ & $2.2 \mathrm{E}+01$ & ND & ND & $<20$ & 1.0 & $0.25 \mathrm{M} / 4.6$ \\
\hline CT14 & $4.79 \mathrm{E}+05$ & $1.8 \mathrm{E}+01$ & ND & ND & $<20$ & 1.1 & $0.25 \mathrm{M} / 4.6$ \\
\hline CT15 & $2.40 \mathrm{E}+05$ & $<1.3 \mathrm{E}+01$ & ND & ND & $<20$ & 0.9 & $0.25 \mathrm{M} / 4.6$ \\
\hline $\mathrm{CT} 16^{\mathrm{c}}$ & $5.40 \mathrm{E}+05$ & $2.0 \mathrm{E}+01$ & 45.0 & ND & $<20$ & 0.8 & $0.25 \mathrm{M} / 4.6$ \\
\hline CT17 & $2.94 \mathrm{E}+05$ & $<1.3 \mathrm{E}+01$ & ND & ND & $<20$ & 0.6 & $0.25 \mathrm{M} / 4.6$ \\
\hline CT18 & $4.11 \mathrm{E}+05$ & $<1.3 \mathrm{E}+01$ & ND & ND & $<20$ & 6.7 & $0.25 \mathrm{M} / 4.6$ \\
\hline CT19 & $3.37 \mathrm{E}+05$ & $<1.3 \mathrm{E}+01$ & ND & ND & $<20$ & 1.3 & $0.25 \mathrm{M} / 4.6$ \\
\hline CT20 & $5.00 \mathrm{E}+06$ & $9.5 \mathrm{E}+01$ & 27.3 & ND & $<20$ & 9.8 & $0.50 M / 4.8$ \\
\hline
\end{tabular}

${ }^{\mathrm{a} C e n t r i f u g e}$ tubes are listed in order of elution.

bFeed/load/raffinate.

"Centrifuge tube " 16 " was resampled two days later because of an inconsistency in the data. The sample showed daughter ingrowth of ${ }^{249} \mathrm{Cf}$.

dNo data. 
Table 11. Mass of ${ }^{249} \mathrm{Bk},{ }^{249} \mathrm{Cf}$, and ${ }^{252} \mathrm{Cf}$ in centrifuge tubes 7-20

\begin{tabular}{c|c|c|c}
\hline Item & $\begin{array}{c}\text { Mass of } \\
\mathbf{2 4 9} \mathbf{B k}, \mathbf{m g}\end{array}$ & $\begin{array}{c}\text { Mass of } \\
\mathbf{2 4 9}^{\mathbf{C f}, \mathbf{m g}}\end{array}$ & $\begin{array}{c}\text { Mass of } \\
\mathbf{2 5 2} \mathbf{C f}, \mathbf{m g}\end{array}$ \\
\hline FLR $^{\mathrm{a}}$ & BDL & BDL & BDL \\
\hline CT7 & BDL & BDL & BDL \\
\hline CT8 & BDL & BDL & BDL \\
\hline CT9 & BDL & 0.01 & 0.01 \\
\hline CT10 & BDL & 0.01 & $7.00 E-3$ \\
\hline CT11 & 0.03 & $2.00 E-3$ & $2.00 E-3$ \\
\hline CT12 & 0.39 & $2.00 E-3$ & BDL \\
\hline CT13 & 0.60 & BDL & BDL \\
\hline CT14 & 1.40 & BDL & BDL \\
\hline CT15 & 1.43 & BDL & BDL \\
\hline CT16 & 1.43 & BDL & BDL \\
\hline CT17 & 1.17 & BDL & BDL \\
\hline CT18 & 18.3 & BDL & BDL \\
\hline CT19 & 1.16 & BDL & BDL \\
\hline CT20 & 0.33 & BDL & BDL \\
\hline
\end{tabular}

${ }^{\mathrm{a} F e e d} / \mathrm{load} / \mathrm{raffinate.}$

${ }^{b}$ Below detectable limits.

\section{C75 Final Cleanup Column}

Centrifuge tubes $14-19$ were selected with a total mass of $24.86 \mathrm{mg}$ of ${ }^{249} \mathrm{Bk}$ and minimal amounts of ${ }^{249} \mathrm{Cf}$, with less than $20 \mathrm{cpm} / \mathrm{mL}$. The centrifuge tubes were split into two fractions and loaded to the final cleanup column, consisting of a $3.0 \mathrm{~mL}$ preconditioned Dowex 50W-X4 (200-400) cation-exchange column. The final product was collected in CT18. Duplicate samples were taken and diluted to be analyzed by liquid scintillation, gamma, alpha, and neutron spectroscopy. The final analysis of the sample is displayed in Table 12 , containing minimal amounts of ${ }^{252} \mathrm{Cf},{ }^{249} \mathrm{Cf}$, and ${ }^{253} \mathrm{Es}$.

Table 12. Analysis of ${ }^{249} \mathrm{Bk}$ solution after final cleanup procedures

\begin{tabular}{c|c}
\hline Isotope & Mass, mg \\
\hline${ }^{249} \mathrm{Bk}$ & $2.66 \mathrm{E}+01$ \\
\hline${ }^{252} \mathrm{Cf}$ & $9.23 \mathrm{E}-07$ \\
\hline${ }^{249} \mathrm{Cf}$ & $2.59 \mathrm{E}-01$ \\
\hline${ }^{253} \mathrm{Es}$ & $1.70 \mathrm{E}-06$ \\
\hline
\end{tabular}

The majority of ${ }^{249} \mathrm{Bk}$ was shipped to customers in both Germany and Russia, with $12.7 \mathrm{mg}$ going to each. The dispensed $\mathrm{Bk}$ was requested as a nitric salt and was dried carefully with a heat lamp to ease in future dissolution. The customers from Russia requested the Bk product to be split in three different quartz tubes, but the customers from Germany requested the Bk product to be split in four glass v-vials. The shipments were shipped on February 27, 2012, and the material was used for experiments to confirm the synthesis of 
tennessine. Dissolution of the ${ }^{249} \mathrm{Bk}$ nitric salt was accomplished with no difficulties by the customers in both Russia and Germany. Customers in Germany deposited the material onto the targets by molecular plating methods onto titanium foil using an electrochemical deposition cell with isobutanol. Customers in Russia used methods mentioned in Section 3.1.

A small aliquot of $10 \mu \mathrm{g}$ was also requested from Argonne National Laboratory with as little ${ }^{249} \mathrm{Cf}$ ingrowth as possible. Another AHIB column, consisting of a $1.0 \mathrm{~mL}$ bed volume of Dowex 50W-X8 (200-400), was completed to separate ${ }^{249} \mathrm{Bk}$ and ${ }^{249} \mathrm{Cf}$ for the shipment to Argonne National Laboratory. However, the column failed due to suspected AHIB deterioration and too small of a bed volume size. Another AHIB column was set up with a $3.0 \mathrm{~mL}$ bed volume and a fresh batch of AHIB solution. The separation was successful, with $0.24 \mathrm{mg}$ of ${ }^{249} \mathrm{Bk}$ and $<0.02 \mathrm{mg}$ of ${ }^{249} \mathrm{Cf}$ (limit of detection) in the final product. An aliquot containing $10 \mu \mathrm{g}$ was sent out on April 12, 2012, in less than 24 hours after the final separation to ensure that minimal ${ }^{249} \mathrm{Cf}$ ingrowth would occur. The remaining ${ }^{249} \mathrm{Bk}$ was used for electrodeposition and column studies at REDC.

\subsection{PRODUCTION CAMPAIGN 76}

Five full-length, mixed-curium targets were irradiated for ${ }^{252} \mathrm{Cf}$ production in HFIR for three cycles and were discharged on November 2, 2014, with a goal of recovering $15 \mathrm{mg}$ of ${ }^{249} \mathrm{Bk}$. After discharging from HFIR at the end of cycle 456, the five targets were placed in the reactor pool to cool until transferring to REDC hot cells on January 7, 2015. Table 13 displays the calculated contents of the irradiated target material for C76 before hot cell processing, which started on February 16, 2015.

Table 13. Calculated feed material for C76

\begin{tabular}{c|c|c|c|c|c|c|c|c|c}
\hline Item & $\begin{array}{c}\mathbf{1 3 1}_{\mathbf{I}} \mathbf{\mathbf { C }} \\
\mathbf{C i}\end{array}$ & $\begin{array}{c}{ }^{241} \mathbf{A m}, \\
\mathbf{g}\end{array}$ & $\begin{array}{c}{ }^{243} \mathbf{A m}, \\
\mathbf{G}\end{array}$ & $\begin{array}{c}\mathbf{C m}, \\
\mathbf{G}\end{array}$ & $\begin{array}{c}{ }^{244} \mathbf{C m}, \\
\mathbf{g}\end{array}$ & $\begin{array}{c}\mathbf{L n}, \\
\mathbf{g}\end{array}$ & $\begin{array}{c}{ }^{249} \mathbf{B k}, \\
\mathbf{m g}\end{array}$ & $\begin{array}{c}{ }^{252} \mathbf{C f}, \\
\mathbf{m g}\end{array}$ & $\begin{array}{c}{ }^{254} \mathbf{E s ,} \\
\mathbf{\mu g}\end{array}$ \\
\hline Irradiated Targets $^{\mathrm{a}}$ & $0.4^{\mathrm{b}}$ & 0 & 1.0 & 34.2 & 7.1 & 1 & 24 & 97 & 2 \\
\hline Rework $^{\mathrm{c}}$ & 0 & 0.8 & 2.1 & 12.3 & 2.9 & 25 & 0 & 13 & 0 \\
\hline Total & 0.4 & 0.8 & 3.1 & 46.5 & 10.0 & 26 & 24 & 110 & 2 \\
\hline
\end{tabular}

aTarget numbers S-42, S-43, S-44, S-45, and S-46.

${ }^{b}$ Includes $0.03 \mathrm{Ci}$ accumulated from ${ }^{252} \mathrm{Cf}$ fissions plus $0.34 \mathrm{Ci}$ left from the fissions during the irradiation.

'Rework includes C75 chemical processing recycle (CY11T23CL-1) and C75 target scrap (35 pellets).

The Berkex batch solvent extraction process was performed on March 23, 2015. After the Berkex batch solvent extraction process was complete, the ${ }^{249} \mathrm{Bk}$ product was sampled and found to contain $15.3 \mathrm{mg}$ of ${ }^{249} \mathrm{Bk}$ by beta and $15.9 \mathrm{mg}$ by alpha, with only $0.12 \mu \mathrm{g}$ of ${ }^{252} \mathrm{Cf}$.

Nathan Sims, Joseph Rayburn, and Shelley Van Cleve carried out the final cleanup procedures outlined in Sections 2.1.1-2.1.5 for $\mathrm{C} 76$ to remove the residual ${ }^{252} \mathrm{Cf}$ from the ${ }^{249} \mathrm{Bk}$ product. Final processing started on May 21, 2015, in an REDC glovebox (7920-211-04) with the TCE scrubbing and volume reduction. After the volume reduction was complete, the solution containing ${ }^{249} \mathrm{Bk}$ was transferred to a $15 \mathrm{~mL}$ glass centrifuge tube labeled "CT1," and the rinse of the boiling flask was transferred to a separate centrifuge tube labeled "CT2." Approximate dose readings were taken using an ion chamber survey meter with a beta slide, shown in Table 14. 
Table 14. Dose rates and volume of CT1 and CT2 after volume reduction

\begin{tabular}{c|c|c|c}
\hline \multirow{2}{*}{ Item } & \multicolumn{2}{|c|}{ Dose Rate, $\mathbf{m R} / \mathbf{h}$} & \multirow{2}{*}{ Volume, $\mathbf{m L}$} \\
\cline { 2 - 3 } & $\begin{array}{c}\text { Open Window } \\
(\boldsymbol{\beta}, \boldsymbol{\gamma})\end{array}$ & $\begin{array}{c}\text { Closed Window } \\
(\boldsymbol{\gamma})\end{array}$ & \\
\hline CT1 & 1600 & 280 & 0.9 \\
\hline CT2 & 40 & 12 & 10 \\
\hline
\end{tabular}

\section{C76 Initial Cleanup Column}

The contents from CT1 were diluted with $100 \mathrm{~mL}$ of deionized water and pressurized through a preconditioned cation-exchange column with Dowex 50W-X4 (200-400) cation-exchange resin and a pearshaped reservoir at a rate of 2 seconds per drop, along with several acid rinses of $0.1 M \mathrm{HNO}_{3}$. CT1 and CT2 were rinsed and cleaned with acid and were reused to collect the eluent of the initial cleanup column. The dose rates and volumes of CT1 and CT2 from the initial cation-exchange column are displayed in Table 15.

Table 15. Dose rates and volumes of CT1 and CT2 after initial cleanup column

\begin{tabular}{c|c|c|c}
\hline \multirow{2}{*}{ Item } & \multicolumn{2}{|c|}{ Dose Rate, $\mathbf{m R} / \mathbf{h}$} & \multirow{2}{*}{ Volume, $\mathbf{m L}$} \\
\cline { 2 - 3 } & $\begin{array}{c}\text { Open Window } \\
(\boldsymbol{\beta}, \boldsymbol{\gamma})\end{array}$ & $\begin{array}{c}\text { Closed Window } \\
(\boldsymbol{\gamma})\end{array}$ & \\
\hline FLR $^{\mathrm{a}}$ & 3 & background & 155 \\
\hline CT1 & 4.2 & 1.6 & 8.50 \\
\hline CT2 & 1650 & 411.5 & 0.45 \\
\hline
\end{tabular}

aFeed/load/raffinate

\section{C76 AHIB Column}

CT2 was selected for the AHIB separation. The contents of CT2 were diluted with $13.5 \mathrm{~mL}$ of deionized water, resulting in a $0.2 \mathrm{M} \mathrm{HCl}$ solution. The feed solution was pressurized through a $3.0 \mathrm{~mL}$ bed volume of preconditioned Dowex 50W-X4 (200-400) cation-exchange resin at a rate of 2 seconds per drop, following the procedures listed in Section 2.1.4. Centrifuge tubes 4 through 9 were used to collect the eluent of the AHIB column. An ion chamber survey meter with a beta slide was used to do a quick evaluation of the samples post-elution. The ion chamber survey meter detected the ${ }^{249} \mathrm{Bk}$ product, but a neutron detector was used to detect the residual ${ }^{252} \mathrm{Cf}$. Small samples were pulled after the column run for liquid scintillation analysis and alpha spectroscopy to determine where the majority of the ${ }^{249} \mathrm{Bk}$ eluted and which fractions would be used in the final cleanup column. The data obtained and analyzed on June 8, 2015, is found in Table 16 and Table 17. 
Table 16. Dose rates and volumes of centrifuge tubes 4-9 from AHIB column separation

\begin{tabular}{|c|c|c|c|c|c|c|c|}
\hline Item $^{a}$ & $\begin{array}{c}{ }^{249} \text { Bk Beta } \\
\text { by Liquid } \\
\text { Scintillation, } \\
\text { Bq/mL } \\
\end{array}$ & $\begin{array}{c}\text { Gross } \alpha, \\
\mathrm{Bq} / \mathrm{mL}\end{array}$ & $\begin{array}{l}5.80 \mathrm{MeV} \alpha \\
{ }^{249} \mathrm{Cf} \%\end{array}$ & $\begin{array}{l}6.11 \mathrm{MeV} \alpha \\
{ }^{252} \mathrm{Cf} \%\end{array}$ & $\begin{array}{c}\text { Gross } \\
\text { neutron, } \\
\text { cpm/mL }\end{array}$ & $\begin{array}{c}\text { Volume, } \\
\text { mL }\end{array}$ & [AHIB]/pH \\
\hline FLR $^{b}$ & $1.98 \mathrm{E}+03$ & $<70$ & $\mathrm{ND}^{\mathrm{c}}$ & ND & $<40$ & 70 & ND \\
\hline CT4 & $6.70 \mathrm{E}+03$ & $1.4 \mathrm{E}+03$ & 49.8 & $\mathrm{ND}$ & $<40$ & 12.4 & $0.25 \mathrm{M} / 4.2$ \\
\hline CT5 & $3.99 \mathrm{E}+04$ & $2.0 \mathrm{E}+02$ & 100.0 & $\mathrm{ND}$ & $<40$ & 3.5 & $0.25 \mathrm{M} / 4.6$ \\
\hline CT6 & $4.00 \mathrm{E}+05$ & $<70$ & $\mathrm{ND}$ & $\mathrm{ND}$ & $1.10 \mathrm{E}+03^{\mathrm{d}}$ & 1.0 & $0.25 \mathrm{M} / 4.6$ \\
\hline CT7 & $6.79 \mathrm{E}+05$ & $<70$ & ND & $\mathrm{ND}$ & $4.90 \mathrm{E}+02^{\mathrm{d}}$ & 0.9 & $0.25 \mathrm{M} / 4.6$ \\
\hline CT8 & $1.62 \mathrm{E}+05$ & $<70$ & ND & $\mathrm{ND}$ & $<40$ & 11.1 & $0.25 \mathrm{M} / 4.6$ \\
\hline CT9 & $3.80 \mathrm{E}+02$ & $<70$ & ND & ND & $<40$ & 10.0 & $0.50 \mathrm{M} / 4.8$ \\
\hline
\end{tabular}

${ }^{a}$ Fractions are listed in order of elution.

${ }^{b}$ Feed/load/raffinate.

'No data.

${ }^{\mathrm{d}}$ A larger sample volume was used to determine the neutron counts for CT6 and CT7 to detect trace amounts of ${ }^{252} \mathrm{Cf}$. 
Table 17. Mass of ${ }^{249} \mathrm{Bk},{ }^{249} \mathrm{Cf}$, and ${ }^{252} \mathrm{Cf}$ in centrifuge tubes 4-9

\begin{tabular}{|c|c|c|c|}
\hline Item & $\begin{array}{c}\text { Mass of } \\
{ }^{249} \mathrm{Bk}, \mathrm{mg}\end{array}$ & $\begin{array}{c}\text { Mass of } \\
{ }^{249} \mathrm{Cf}, \mathrm{mg}\end{array}$ & $\begin{array}{l}\text { Mass of } \\
{ }^{252} \mathrm{Cf}, \mathrm{mg}\end{array}$ \\
\hline FLR $^{\mathrm{a}}$ & ${ }^{b} B D L$ & BDL & BDL \\
\hline CT4 & BDL & 0.02 & BDL \\
\hline CT5 & 0.37 & 0.63 & BDL \\
\hline CT6 & 1.06 & 0.04 & $1.67 \mathrm{E}-07$ \\
\hline CT7 & 1.62 & 0.02 & $1.34 \mathrm{E}-07$ \\
\hline CT8 & 11.9 & 0.12 & BDL \\
\hline СТ9 & BDL & BDL & BDL \\
\hline
\end{tabular}

\section{C76 Final Cleanup Column}

CT6, CT7, and CT8 were selected for the final cation cleanup. CT8 was pressurized through the cleanup column a week before CT6 and CT7. The purpose of delaying CT6 and CT7 in the final cation cleanup was to reverify the amount of ${ }^{249} \mathrm{Bk}$ in CT6 and CT7 to determine if there was enough material worth retrieving. After submitting a second set of samples for analytical results, CT6 and CT7 were selected to go through the final cation cleanup column as well.

A final cation-exchange cleanup column was performed with CT8, containing $11.93 \mathrm{mg}$ of ${ }^{249} \mathrm{Bk}$, on June 10, 2015. After the feed solution acidity was adjusted with $6 \mathrm{M} \mathrm{HCl}$ and deionized water, the feed solution acidity was around $0.2 \mathrm{M}$ with a total volume of $13.5 \mathrm{~mL}$. The solution was pressurized through a preconditioned Dowex 50W-X4 (200-400) cation-exchange column at a rate of 2-3 seconds per drop. Centrifuge tubes 10 and 11 were used to collect the eluent of the first run. The dose rates from the centrifuge tubes are displayed in Table 17.

Table 18. Dose rates and volumes of centrifuge tubes 10 and 11 after final cleanup column

\begin{tabular}{c|c|c|c}
\hline \multirow{2}{*}{ Item } & \multicolumn{2}{|c|}{ Dose Rate, $\mathbf{m R} / \mathbf{h}$} & \multirow{2}{*}{ Volume, $\mathbf{m L}$} \\
\cline { 2 - 3 } & $\begin{array}{c}\text { Open Window } \\
(\boldsymbol{\beta}, \boldsymbol{\gamma})\end{array}$ & $\begin{array}{c}\text { Closed Window } \\
(\boldsymbol{\gamma})\end{array}$ & 50 \\
\hline FLR $^{\mathrm{a}}$ & background & background & 7.5 \\
\hline $\mathrm{CT}^{*} 10$ & 420 & 200 & 9.1 \\
\hline CT11 & 1 & background & 5 \\
\hline
\end{tabular}

${ }^{\mathrm{a}} \mathrm{Feed} /$ load/raffinate.

The same final cation-exchange cleanup column was used for centrifuge tubes 6 and 7 on June 17, 2015. Deionized water saturated the column and resin until it was used a week later. After pressurizing $9 \mathrm{~mL}$ of $0.1 \mathrm{M} \mathrm{HCl}$ through the column, CT6 and CT7 were added and pressurized through the column along with the analytical samples of the centrifuges. CT12 and CT13 were used to collect the eluent of the second run. The dose rates from the centrifuge tubes are displayed in Table 19. 
Table 19. Dose rates and volumes of centrifuge tubes 12 and 13 after final cleanup column

\begin{tabular}{c|c|c|c}
\hline \multirow{2}{*}{ Item } & \multicolumn{2}{|c|}{ Dose Rate, $\mathbf{m R} / \mathbf{h}$} & \multirow{2}{*}{ Volume, $\mathbf{m L}$} \\
\cline { 2 - 3 } & $\begin{array}{c}\text { Open Window } \\
(\boldsymbol{\beta}, \boldsymbol{\gamma})\end{array}$ & $\begin{array}{c}\text { Closed Window } \\
(\boldsymbol{\gamma})\end{array}$ & \\
\hline FLR $^{\mathrm{a}}$ & 9 & 6 & 110 \\
\hline $\mathrm{CT}_{12}$ & 140 & 46 & 9.1 \\
\hline CT13 & 11 & 6 & 9.2 \\
\hline
\end{tabular}

${ }^{\mathrm{a}}$ Feed/load/raffinate.

The contents of CT12 were combined with the Bk from the first column run contained in CT10, and CT12 was cleaned with two $1 \mathrm{~mL}$ rinses of $0.1 \mathrm{M} \mathrm{HCl}$. The rinses were also added to CT10. After the rinses were added, the combined contents in CT10 were evaporated down to $\sim 0.55 \mathrm{~mL}$ using a heating lamp. Deionized water was added up to a total volume of $5 \mathrm{~mL}$ and sampled. An analysis of the final product is displayed in Table 20.

Table 20. Analysis of ${ }^{249} \mathrm{Bk}$ solution after final cleanup procedures

\begin{tabular}{c|c}
\hline Isotope & Mass, $\mathbf{m g}$ \\
\hline${ }^{249} \mathrm{Bk}$ & $1.35 \mathrm{E}+01$ \\
\hline${ }^{252} \mathrm{Cf}$ & $7.38 \mathrm{E}-07$ \\
\hline${ }^{249} \mathrm{Cf}$ & $5.19 \mathrm{E}-01$ \\
\hline
\end{tabular}

The berkelium solution was split between five different customers, with most of the berkelium going to Florida State University. Other customers included Lawrence Berkeley National Laboratory, Radiological Protection Operations at Oak Ridge National Laboratory, Colorado School of Mines, and Chalk River Laboratories. All samples were evaporated using a heating lamp for shipping, and the Florida State University samples were sent as a dried nitrate salt. Table 21 displays the shipping details for each customer, along with the amount of ${ }^{249} \mathrm{Bk}$ sent. The material shipped to both Florida State University and Colorado School of Mines was used for ${ }^{249} \mathrm{Bk}$ complex characterization studies using crystal x-ray diffraction, which was published in Science in August 2016 [7]. 
Table 21. Dispensing and shipping details of ${ }^{249} \mathrm{Bk}$ solution for $\mathrm{C76}$

\begin{tabular}{|c|c|c|c|c|c|c|c|}
\hline Customer & $\begin{array}{c}\text { Date } \\
\text { Dispensed }\end{array}$ & $\begin{array}{c}\text { Date } \\
\text { Shipped }\end{array}$ & ${ }^{249} \mathrm{Bk}, \mu \mathrm{g}$ & ${ }^{249} \mathrm{Cf}, \mu \mathrm{g}$ & ${ }^{252} \mathrm{Cf}, \mu \mathrm{g}$ & $\begin{array}{c}\text { Total } \\
\text { Volume } \\
\text { Dispensed, } \\
\mu \mathrm{L} \\
\end{array}$ & Packaging \\
\hline $\begin{array}{c}\text { Lawrence } \\
\text { Berkeley } \\
\text { National } \\
\text { Laboratory }\end{array}$ & $\begin{array}{c}\text { June } 26 \text {, } \\
2015\end{array}$ & $\begin{array}{c}\text { July } 7 \text {, } \\
2015\end{array}$ & $1.00 \mathrm{E}+02$ & $3.90 \mathrm{E}+00$ & $5.50 \mathrm{E}-06$ & $1.85 \mathrm{E}+03$ & Two v-vials \\
\hline $\begin{array}{l}\text { Colorado } \\
\text { School of } \\
\text { Mines }\end{array}$ & $\begin{array}{c}\text { June } 29, \\
2015\end{array}$ & $\begin{array}{c}\text { July 14, } \\
2015\end{array}$ & $5.00 \mathrm{E}-01$ & $1.90 \mathrm{E}-02$ & $2.80 \mathrm{E}-08$ & $9.27 \mathrm{E}+02$ & One v-vial \\
\hline $\begin{array}{c}\text { Florida State } \\
\text { University }\end{array}$ & $\begin{array}{c}\text { June 24, } \\
2015\end{array}$ & $\begin{array}{l}\text { July } 21, \\
2015\end{array}$ & $1.30 \mathrm{E}+04$ & $5.00 \mathrm{E}+02$ & $7.10 \mathrm{E}-04$ & $4.80 \mathrm{E}+03$ & Three v-vials \\
\hline $\begin{array}{l}\text { Radiological } \\
\text { Protection } \\
\text { Operations at } \\
\text { Oak Ridge } \\
\text { National } \\
\text { Laboratory }\end{array}$ & $\begin{array}{c}\text { July } 27, \\
2015\end{array}$ & $\begin{array}{c}\text { July } 28 \text {, } \\
2015\end{array}$ & $1.65 \mathrm{E}-01$ & $6.35 \mathrm{E}-06$ & $9.03 \mathrm{E}-12$ & $1.00 \mathrm{E}+05$ & One v-vial \\
\hline $\begin{array}{l}\text { Chalk River } \\
\text { Laboratories }\end{array}$ & $\begin{array}{c}\text { July } 29 \\
2015\end{array}$ & $\begin{array}{l}\text { August 12, } \\
2015\end{array}$ & $1.00 \mathrm{E}-01$ & $4.20 \mathrm{E}-03$ & $6.00 \mathrm{E}-09$ & $2.02 \mathrm{E}+00$ & One v-vial \\
\hline
\end{tabular}

\subsection{PRODUCTION CAMPAIGN 77}

\subsection{1. $\quad{ }^{249}$ Bk Recovery}

Six full-length, mixed-curium targets were irradiated for ${ }^{252} \mathrm{Cf}$ production in HFIR with a goal of recovering $8 \mathrm{mg}$ of ${ }^{249} \mathrm{Bk}$. Two of the targets consisted of "heavy" curium $\left(\sim 20 \mathrm{wt} \%{ }^{244} \mathrm{Cm}\right)$, and the other four targets consisted of "light" curium $\left(\sim 70 \mathrm{wt} \%{ }^{244} \mathrm{Cm}\right)$ that was used in previous $\mathrm{Cm}$ projects. The "light" curium targets were irradiated for four cycles in the beryllium reflector and four cycles in the flux trap, and they were discharged from HFIR on September 30, 2016. The "heavy" curium targets were irradiated for nine cycles in the flux trap and were discharged on December 9, 2016. After 3 weeks allotted for cooling in the reactor pool, the targets were transferred back to the REDC hot cells on December 28, 2016. Table 22 displays the calculated contents of the irradiated target material for $\mathrm{C} 77$ before hot cell processing. 
Table 22. Calculated feed material for $\mathrm{C} 77$

\begin{tabular}{c|c|c|c|c|c|c|c|c|c}
\hline Item & $\begin{array}{c}\mathbf{1 3 1} \mathbf{I}, \\
\mathbf{C i}\end{array}$ & $\begin{array}{c}{ }^{\mathbf{2 4 1}} \mathbf{A m}, \\
\mathbf{g}\end{array}$ & $\begin{array}{c}{ }^{243} \mathbf{A m}, \\
\mathbf{g}\end{array}$ & $\begin{array}{c}\mathbf{C m}, \\
\mathbf{g}\end{array}$ & $\begin{array}{c}{ }^{244} \mathbf{C m}, \\
\mathbf{g}\end{array}$ & $\begin{array}{c}\mathbf{L n}, \\
\mathbf{g}\end{array}$ & $\begin{array}{c}{ }^{249} \mathbf{B k}, \\
\mathbf{m g}\end{array}$ & $\begin{array}{c}{ }^{252} \mathbf{C f}, \\
\mathbf{m g}\end{array}$ & $\begin{array}{c}{ }^{254} \mathbf{E s}, \\
\mathbf{\mu g}\end{array}$ \\
\hline $\begin{array}{c}\text { "Heavy" Curium } \\
\text { Targets }^{\mathrm{a}}\end{array}$ & 1.40 & - & 0.06 & 11.4 & 1.9 & 0.8 & 11 & 79 & 2.1 \\
\hline $\begin{array}{c}\text { "Light" Curium } \\
\text { Targets }^{\mathrm{b}}\end{array}$ & 0.01 & - & 0.27 & 15.3 & 10.6 & 1.4 & 2 & 8 & 0.1 \\
\hline Rework & - & 0.1 & 0.91 & 3.7 & 1.0 & 4.0 & - & 7 & - \\
\hline Total & $1.41^{\mathrm{d}}$ & 0.1 & 1.2 & 30.4 & 13.5 & 6.2 & 13 & 94 & 2.2 \\
\hline
\end{tabular}

aTarget numbers S-51 and S-52.

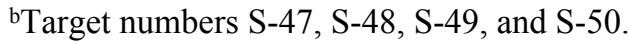

${ }^{\mathrm{c} R e w o r k}$ includes $\mathrm{C} 76$ chemical processing recycle (76OX-1 through 4), and C75 target scrap.

${ }^{\mathrm{d}}$ It is estimated that $\sim 0.002 \mathrm{Ci}$ from will be generated per day from the fissions of ${ }^{252} \mathrm{Cf}$ until the ${ }^{252} \mathrm{Cf}$ is encapsulated for transfer to Building 7930.

The Berkex batch solvent extraction process was performed on March 28, 2017. After the Berkex batch solvent extraction process was complete, the ${ }^{249} \mathrm{Bk}$ product was sampled and found to contain $13.51 \mathrm{mg}$ of ${ }^{249} \mathrm{Bk}$ by beta scintillation with only $0.99 \mu \mathrm{g}$ of ${ }^{252} \mathrm{Cf}$ by alpha scintillation.

Nathan Sims, Tony Dyer, and Shelley Van Cleve completed the final cleanup procedures outlined in Sections 2.1.1-2.1.5 for $\mathrm{C} 77$ to remove the residual ${ }^{252} \mathrm{Cf}$ from the ${ }^{249} \mathrm{Bk}$ product. Organic scrubbing with TCE started on June 7, 2017, and was followed by volume reduction on June 13, 2017. From the volume reduction, the product was transferred to a centrifuge tube labeled "CT1," and the rinse of the boiling flask with $10 \mathrm{~mL}$ of $0.1 \mathrm{M} \mathrm{HNO}_{3}$ was transferred to a centrifuge tube labeled "CT2." The dose rates from the centrifuge tubes are displayed in Table 23.

Table 23. Dose rates and volumes of CT1 and CT2 after volume reduction

\begin{tabular}{c|c|c|c}
\hline \multirow{2}{*}{ Item } & \multicolumn{2}{|c|}{ Dose Rate, $\mathbf{m R} / \mathbf{h}$} & \multirow{2}{*}{ Volume, $\mathbf{~ m L}$} \\
\cline { 2 - 3 } & $\begin{array}{c}\text { Open Window } \\
(\boldsymbol{\beta}, \boldsymbol{\gamma})\end{array}$ & $\begin{array}{c}\text { Closed Window } \\
(\boldsymbol{\gamma})\end{array}$ & 1.9 \\
\hline CT1 & 3100 & 239 & 10.1 \\
\hline CT2 & 54 & 8 & \\
\hline
\end{tabular}

The volume of the concentrated solution in CT1 was further reduced so that the total feed volume for the initial cation-exchange column could be reduced. This was accomplished by placing CT1 into an evaporation unit with infrared heat and argon gas flow, allowing the concentrated solution to be reduced to $0.9 \mathrm{~mL}$. White solids were observed after the evaporation but were dissolved with $1 \mathrm{~mL}$ of $0.1 \mathrm{M} \mathrm{HCl}$. The solids were sampled and confirmed to contain ${ }^{249} \mathrm{Bk}$ activity. The contents of CT1 were then transferred to the initial cation column load bottle and diluted with $70 \mathrm{~mL}$ of deionized water, resulting in a concentration of $\sim 0.2 \mathrm{M} \mathrm{HNO}_{3}$.

\section{C77 ${ }^{249}$ Bk Initial Cleanup Column}

The contents of CT2 were loaded onto the initial cleanup column, which consisted of a $3.0 \mathrm{~mL}$ bed volume of Dowex 50W-X4 (200-400) cation-exchange resin with a pear-shaped reservoir column. After CT2 was 
loaded, the initial cation column bottle contents containing CT1 were loaded onto the column with the dissolved white solids. The solution was pressurized through the column at a rate of 1.5-2 seconds per drop following the procedure outlined in Section 2.1.3. The eluent was collected in the centrifuge tubes listed in Table 24

Table 24. Dose rates and volumes of centrifuge tubes 3-10 after initial cleanup column

\begin{tabular}{c|c|c|c}
\hline \multirow{2}{*}{ Item } & \multicolumn{2}{|c|}{ Dose Rate, $\mathbf{m R} / \mathbf{h}$} & \multirow{2}{*}{ Volume, $\mathbf{m L}$} \\
\cline { 2 - 3 } & $\begin{array}{c}\text { Open Window } \\
(\boldsymbol{\beta}, \boldsymbol{\gamma})\end{array}$ & $\begin{array}{c}\text { Closed Window } \\
(\boldsymbol{\gamma})\end{array}$ & \\
\hline FLR $^{\mathrm{a}}$ & 1.7 & 1.3 & 130 \\
\hline CT3 & 2.9 & 1.8 & 4.5 \\
\hline CT4 & 3.3 & 2.2 & 2.3 \\
\hline CT5 & 1.9 & 1.5 & 2.5 \\
\hline CT6 & 2.5 & 1.7 & 1.0 \\
\hline CT7 & 1700 & 180 & 4.8 \\
\hline CT8 & 37 & 1.5 & 2.0 \\
\hline CT9 & 1.9 & 1.4 & 6.0 \\
\hline CT10 & 1.7 & 1.6 & 8.8 \\
\hline
\end{tabular}

${ }^{\mathrm{a} F e e d / l o a d / r a f f i n a t e .}$

\section{C77 ${ }^{249}$ Bk AHIB Column}

CT7 was brought to dryness with an evaporation unit using infrared heat with an argon gas sweep. CT6 and CT8 were transferred to CT7 and were also brought to dryness in preparation for the AHIB separation. The contents of CT7 were dissolved in $2 \mathrm{~mL}$ of $0.1 \mathrm{M} \mathrm{HCl}$ and were left to sit for two nights. The feed solution was pressurized through a $3.0 \mathrm{~mL}$ bed volume of preconditioned Dowex 50W-X4 (200-400) cationexchange resin at a rate of 2 seconds per drop, following the procedures listed in Section 2.1.4. An ion chamber survey meter with a beta slide was used to do a quick evaluation of the samples post-elution. The ion chamber survey meter detected the ${ }^{249} \mathrm{Bk}$ product, and a neutron detector was used to detect the residual ${ }^{252} \mathrm{Cf}$. After the column run, small samples were pulled for liquid scintillation analysis and alpha spectroscopy to determine where the majority of the ${ }^{249} \mathrm{Bk}$ eluted and which fractions would be used in the final cleanup column. The eluent was collected with centrifuge tubes 11-17, displayed in Table 25 and Table 26. 
Table 25. Dose rates and volumes of centrifuge tubes 11-17 and FLR after AHIB separation

\begin{tabular}{|c|c|c|c|c|c|c|c|}
\hline Item $^{\mathbf{a}}$ & $\begin{array}{c}{ }^{249} \text { Bk Beta } \\
\text { by Liquid } \\
\text { Scintillation, } \\
\text { Bq/mL }\end{array}$ & $\begin{array}{c}\text { Gross } \alpha \\
\text { Bq/mL }\end{array}$ & $\begin{array}{l}5.80 \mathrm{MeV} \alpha \\
{ }^{249} \mathrm{Cf} \%\end{array}$ & $\begin{array}{l}\text { 6.11 MeV } \alpha \\
{ }^{252} \mathrm{Cf} \%\end{array}$ & $\begin{array}{c}\text { Gross } \\
\text { neutron, } \\
\text { cpm } / \mathbf{m L}\end{array}$ & $\begin{array}{c}\text { Volume, } \\
\text { mL }\end{array}$ & {$[\mathbf{A H I B}] / \mathbf{p H}$} \\
\hline $\mathrm{FLR}^{\mathrm{b}}$ & $2.20 \mathrm{E}+02$ & $2.20 \mathrm{E}+01$ & $\mathrm{ND}^{\mathrm{c}}$ & ND & $<80$ & 130 & $0.25 \mathrm{M} / 4.2$ \\
\hline CT11 & $2.20 \mathrm{E}+04$ & $5.2 \mathrm{E}+04$ & 93.5 & 4.7 & 430 & 13.0 & $0.25 \mathrm{M} / 4.6$ \\
\hline CT12 & $1.80 \mathrm{E}+06$ & $1.1 \mathrm{E}+05$ & 87.8 & 3.1 & 840 & 2.40 & $0.25 \mathrm{M} / 4.6$ \\
\hline CT13 & $3.20 \mathrm{E}+07$ & $2.0 \mathrm{E}+04$ & 92 & 3.3 & 130 & 1.15 & $0.25 \mathrm{M} / 4.6$ \\
\hline CT14 & $4.70 \mathrm{E}+05$ & $1.4 \mathrm{E}+01$ & 64.2 & ND & $<80$ & 2.05 & $0.25 \mathrm{M} / 4.6$ \\
\hline CT15 & $4.40 \mathrm{E}+05$ & $1.3 \mathrm{E}+01$ & 41.2 & ND & $<80$ & 11.0 & $0.25 \mathrm{M} / 4.6$ \\
\hline CT16 & $9.20 \mathrm{E}+02$ & $<13$ & 100 & ND & $<80$ & 10.1 & $0.50 \mathrm{M} / 4.8$ \\
\hline CT17 & $3.80 \mathrm{E}+02$ & $<13$ & 25 & ND & $<80$ & 10.3 & ND \\
\hline
\end{tabular}

${ }^{\mathrm{a} C e n t r i f u g e ~ t u b e s ~ a r e ~ l i s t e d ~ i n ~ o r d e r ~ o f ~ e l u t i o n . ~}$

${ }^{\mathrm{b}}$ Feed/load/raffinate.

cNo data.

Table 26. Mass of ${ }^{249} \mathrm{Bk},{ }^{249} \mathrm{Cf}$, and ${ }^{252} \mathrm{Cf}$ in centrifuge tubes $11-17$ after AHIB separation

\begin{tabular}{c|c|c|c}
\hline Item & $\begin{array}{c}\text { Mass of } \\
{ }^{249} \mathbf{B k}, \mathbf{~ m g}\end{array}$ & $\begin{array}{c}\text { Mass of } \\
{ }^{\mathbf{2 4 9}} \mathbf{C f}, \mathbf{~ m g}\end{array}$ & $\begin{array}{c}\text { Mass of } \\
{ }^{\mathbf{2 5 2}} \mathbf{C f}, \mathbf{~} \mathbf{g}\end{array}$ \\
\hline FLR $^{\mathrm{a}}$ & $\mathrm{BDL}$ & $\mathrm{BDL}$ & $\mathrm{BDL}$ \\
\hline $\mathrm{CT} 11$ & $\mathrm{BDL}$ & 0.47 & $\mathrm{BDL}$ \\
\hline $\mathrm{CT} 12$ & 0.01 & 0.17 & $\mathrm{BDL}$ \\
\hline $\mathrm{CT} 13$ & 0.06 & 0.02 & $\mathrm{BDL}$ \\
\hline $\mathrm{CT} 14$ & 0.64 & $\mathrm{BDL}$ & $\mathrm{BDL}$ \\
\hline $\mathrm{CT} 15$ & 11.2 & $\mathrm{BDL}$ & $\mathrm{BDL}$ \\
\hline $\mathrm{CT} 16$ & 0.02 & $\mathrm{BDL}$ & $\mathrm{BDL}$ \\
\hline $\mathrm{CT} 17$ & $\mathrm{BDL}$ & $\mathrm{BDL}$ & $\mathrm{BDL}$ \\
\hline
\end{tabular}

${ }^{\mathrm{a} F e e d / l o a d / r a f f i n a t e .}$

${ }^{\mathrm{b}}$ Below detectable limits.

\section{C77 ${ }^{249}$ Bk Final Cleanup Column}

To avoid adding any residual amounts of ${ }^{252} \mathrm{Cf}$ back into the pure ${ }^{249} \mathrm{Bk}$ product, $\mathrm{CT} 15$ was the only fraction chosen for the final cation-exchange cleanup column. To bring the concentration of CT15 between 0.1 and $0.3 \mathrm{M}$ for the final cation-exchange cleanup column loading, $0.55 \mathrm{~mL}$ of $6 \mathrm{M} \mathrm{HCl}$ was added to the centrifuge tube. The feed solution from CT15 with a total volume of $11.5 \mathrm{~mL}$ was added to the final cationexchange column, which consisted of a $3.0 \mathrm{~mL}$ bed volume of Dowex 50W-X4 (200-400) cation-exchange resin. The feed solution was pressurized through the column with argon gas at a rate of 2 seconds per drop, along with $15 \mathrm{~mL}$ of $0.1 \mathrm{M} \mathrm{HCl}$. After several additional rinses of acid, centrifuge tubes CT18, CT19, and CT20 were used to collect the eluent. The dose rates and volumes of these tubes are displayed in Table 27. 
Table 27. Dose rates and volumes of centrifuge tubes 18-20 after final cleanup column

\begin{tabular}{c|c|c|c}
\hline \multirow{2}{*}{ Item } & \multicolumn{2}{|c|}{ Dose Rate, $\mathbf{m R} / \mathbf{h}$} & \multirow{2}{*}{ Volume, $\mathbf{m L}$} \\
\cline { 2 - 3 } & $\begin{array}{c}\text { Open Window } \\
(\boldsymbol{\beta}, \boldsymbol{\gamma})\end{array}$ & $\begin{array}{c}\text { Closed Window } \\
(\boldsymbol{\gamma})\end{array}$ & 32 \\
\hline FLR $^{\mathrm{a}}$ & background & background & 6.8 \\
\hline $\mathrm{CT}^{2} 8$ & background & background & 10.5 \\
\hline $\mathrm{CT} 19$ & 150 & 100 & 9.8 \\
\hline $\mathrm{CT} 20$ & background & background & \\
\hline
\end{tabular}

aFeed/load/raffinate.

CT19 was evaporated down to $5.5 \mathrm{~mL}$ and sampled. After sampling, the contents were further evaporated to $0.5 \mathrm{~mL}$ and transferred to a v-vial labeled "C77BkPROD." After further evaporation, the product was cleaned using four drops of both hydrogen peroxide $\left(\mathrm{H}_{2} \mathrm{O}_{2}\right)$ and $8 M \mathrm{HNO}_{3}$. The solution was brought to dryness and dissolved in $0.5 \mathrm{~mL}$ of $2 \mathrm{M} \mathrm{HCl}$ to convert the solid into a chloride salt. The converted chloride salt was brought to dryness again and dissolved in $3 \mathrm{~mL}$ of $2 \mathrm{M} \mathrm{HCl}$ for final Bk sampling and dispensing. An analysis of the final product is displayed in Table 28.

Table 28. Analysis of ${ }^{249} \mathrm{Bk}$ solution after final cleanup procedures for $\mathrm{C} 77$

\begin{tabular}{|c|c|}
\hline Isotope & Mass, mg \\
\hline${ }^{249} \mathrm{Bk}$ & $1.03 \mathrm{E}+01$ \\
\hline${ }^{252} \mathrm{Cf}$ & $<4.69 \mathrm{E}-07^{\mathrm{a}}$ \\
\hline${ }^{249} \mathrm{Cf}$ & $3.96 \mathrm{E}-01$ \\
\hline
\end{tabular}

The final product was shipped to Lawrence Berkeley National Laboratory, Florida State University, and Colorado School of Mines in four different shipments between July 21, 2017, and September 15, 2017. Table 29 displays the isotope, shipping details, and customer information for each shipment. 
Table 29. Dispensing and shipping details of ${ }^{249} \mathrm{Bk}$ solution for $\mathrm{C} 77$

\begin{tabular}{c|c|c|c|c|c|c}
\hline Customer & $\begin{array}{c}\text { Date } \\
\text { Shipped }\end{array}$ & ${ }^{249} \mathbf{B k}, \mu \mathrm{g}$ & ${ }^{249} \mathbf{C f}, \boldsymbol{\mu g}$ & ${ }^{252} \mathbf{C f}, \boldsymbol{\mu g}$ & $\begin{array}{c}\text { Total } \\
\text { Volume } \\
\text { Dispensed, } \\
\boldsymbol{\mu L}\end{array}$ & Packaging \\
\hline $\begin{array}{c}\text { Florida State } \\
\text { University }\end{array}$ & $\begin{array}{c}\text { July 21, } \\
2017\end{array}$ & $8.50 \mathrm{E}+03$ & $3.27 \mathrm{E}+02$ & $<3.90 \mathrm{E}-04$ & $2.48 \mathrm{E}+03$ & Two v-vials \\
\hline $\begin{array}{c}\text { Colorado } \\
\text { School of } \\
\text { Mines }\end{array}$ & $\begin{array}{c}\text { July } 31, \\
2017\end{array}$ & $5.00 \mathrm{E}-01$ & $1.90 \mathrm{E}-02$ & $<2.20 \mathrm{E}-08$ & $2.59 \mathrm{E}-01$ & One v-vial \\
\hline $\begin{array}{c}\text { Lawrence } \\
\text { Berkeley } \\
\text { National }\end{array}$ & $\begin{array}{c}\text { July } 31, \\
\text { Laboratory }\end{array}$ & $1.00 \mathrm{E}+02$ & $3.90 \mathrm{E}+00$ & $<4.60 \mathrm{E}-06$ & $3.00 \mathrm{E}+01$ & Two v-vials \\
\hline $\begin{array}{c}\text { Lawrence } \\
\text { Berkeley } \\
\text { National } \\
\text { Laboratory }\end{array}$ & $\begin{array}{c}\text { Sept. 15, } \\
2017\end{array}$ & $1.28 \mathrm{E}+03$ & $2.28 \mathrm{E}+02$ & $1.00 \mathrm{E}-04$ & $1.28 \mathrm{E}+03$ & Three v-vials \\
\hline
\end{tabular}

\subsection{2. $\quad{ }^{254}$ Es Recovery}

Along with ${ }^{249} \mathrm{Bk}$ recovery for $\mathrm{C} 77$, there was a goal of also recovering $1 \mu \mathrm{g}$ of ${ }^{254} \mathrm{Es}$ from the six full-length targets irradiated for ${ }^{252} \mathrm{Cf}$ production in HFIR. The isotopic make-up of the targets for $\mathrm{C} 77$ after irradiation before hot cell processing is displayed in Table 22 located in Section 3.4.1. The fraction containing ${ }^{254}$ Es in the hot cell separation undergoes chemical processing through the Cleanex batch solvent extraction, $\mathrm{LiCl}$ anion exchange, $\mathrm{LiOH}$ precipitation, deep-bed filtration, and ion exchange using AHIB column separation in order to separate ${ }^{252} \mathrm{Cf}$ and other $\mathrm{Cm}$ target material. The ${ }^{254} \mathrm{Es}$ fraction does not undergo the Berkex batch solvent extraction process with the ${ }^{249} \mathrm{Bk}$ material. Instead, the ${ }^{254} \mathrm{Es}$ fraction obtained from the AHIB column separation is transferred into a glovebox at REDC for further processing.

Nathan Sims, Shelley Van Cleve, and Rose Boll carried out the final cleanup procedures in C77 to purify and isolate the ${ }^{254} \mathrm{Es}$ product from other contamination after the hot cell separation steps. A $500 \mathrm{~mL}$ transfer bottle from the hot cell was bagged into a glovebox (7920-209-12) on April 25, 2017, containing $208 \mathrm{~mL}$ of AHIB solution with $2.7 \mu \mathrm{g}$ of ${ }^{254} \mathrm{Es}, 20 \mu \mathrm{g}$ of ${ }^{253} \mathrm{Es}$, and $0.477 \mu \mathrm{g}$ of ${ }^{252} \mathrm{Cf}$. The contents of the $500 \mathrm{~mL}$ poly bottle were transferred to a new bottle with $30 \mathrm{~mL}$ of $0.1 \mathrm{M} \mathrm{HCl}$, giving a final concentration and volume of $\sim 0.27 \mathrm{M}$ and $238 \mathrm{~mL}$ to be loaded onto a concentrator cation column.

\section{C77 ${ }^{254}$ Es Initial Cleanup Column}

The concentrator column consisted of the same setup as an initial cation-exchange column displayed in Figure 8, with a $3.0 \mathrm{~mL}$ bed volume of AG50X4 (200-400) cation-exchange resin and a $250 \mathrm{~mL}$ glass reservoir instead of a $150 \mathrm{~mL}$ glass reservoir. The ${ }^{254}{ }^{2} \mathrm{Es}$ solution was loaded onto the cation-exchange column on April 28, 2017, along with several rinses of $0.1 \mathrm{M}$ and $0.25 \mathrm{M} \mathrm{HCl}$. The solution was pressurized through the column at a rate of 2 seconds per drop. After the procedures listed in Section 2.2.1, the column was rinsed and stripped with $2 \mathrm{M}$ and $6 \mathrm{M} \mathrm{HCl}$. The eluent was collected in several centrifuge tubes and two feed, load, and raffinate bottles displayed in Table 30. 
Table 30. Dose rates and volumes of centrifuge tubes 1-5 after concentrator cation-exchange column

\begin{tabular}{c|c|c|c}
\hline \multirow{2}{*}{ Item $^{\mathbf{a}}$} & \multicolumn{2}{|c|}{ Dose Rate } & \multirow{2}{*}{ Volume, $\mathbf{~ m L}$} \\
\cline { 2 - 3 } & $\begin{array}{c}\text { Neutron, } \\
\mathbf{m r e m} / \mathbf{h}\end{array}$ & $\begin{array}{c}\text { Gamma, } \\
\mathbf{m R} / \mathbf{h}\end{array}$ & 175 \\
\hline FLR1 $^{\mathrm{b}}$ & 1.0 & 1.6 & 115 \\
\hline FLR2 $^{\mathrm{b}}$ & 0.35 & 1.5 & 3.9 \\
\hline CT1 & 0.3 & 0.8 & 7.5 \\
\hline CT2 & 110 & 600 & 9.8 \\
\hline CT3 & 0.3 & 1.0 & 9.3 \\
\hline CT4 & 0.2 & 0.8 & 9.1 \\
\hline CT5 & 0.4 & 0.8 &
\end{tabular}

${ }^{a}$ Centrifuge tubes are listed in order of elution.

${ }^{\mathrm{b}}$ Feed/load/raffinate.

\section{C77 ${ }^{254}$ Es AHIB Column 1}

The next step of the ${ }^{254}$ Es purification and isolation process was an AHIB column separation. A waterjacketed micro-glass column was used with an $8 \mathrm{~mm}$ outer diameter and a $6 \mathrm{~mm}$ inner diameter. The column consisted of a $1.5 \mathrm{~mL}$ bed volume of AG50W-X8 (200-400) cation-exchange resin. CT2 was chosen for the AHIB column separation. CT2 was dried to a solid, and then brought back up in $2 \mathrm{~mL}$ of $0.25 \mathrm{M} \mathrm{HCl}$ before the AHIB run. The product tube was loaded onto the column along with a $1 \mathrm{~mL}$ rinse of $0.25 \mathrm{M} \mathrm{HCl}$ of the centrifuge tube, and the solution was pressurized through the column at a rate of 2 seconds per drop. The procedures listed in Section 2.2.2. were followed for conversion of the column resin, rinsing, and stripping the product. Table 31 displays the dose rates and volumes of the centrifuge tubes and FLR bottles collected during the AHIB column run. 
Table 31. Dose rates and volumes of centrifuge tubes 6-19 after first AHIB column

\begin{tabular}{|c|c|c|c|c|}
\hline \multirow[b]{2}{*}{ Item } & \multicolumn{2}{|c|}{ Dose Rate } & \multirow[b]{2}{*}{ Volume, mL } & \multirow[b]{2}{*}[\mathrm{AHIB}]{$/ \mathbf{p H}$} \\
\hline & $\begin{array}{c}\begin{array}{c}\text { Neutron, } \\
\text { mrem/h} /\end{array} \\
\end{array}$ & $\begin{array}{c}\text { Gamma, } \\
\mathrm{mR} / \mathrm{h}\end{array}$ & & \\
\hline FLR $^{\mathrm{a}}$ & $\mathrm{ND}^{\mathrm{c}}$ & 2 & 17 & ND \\
\hline CONVERSION $^{\mathrm{b}}$ & ND & 1.4 & 25 & ND \\
\hline CT6 & ND & 0.8 & 5.4 & ND \\
\hline CT7 & ND & 0.8 & 10.7 & $0.25 \mathrm{M} / 3.8$ \\
\hline CT8 & ND & 0.9 & 5.35 & $0.25 \mathrm{M} / 3.8$ \\
\hline CT9 & ND & 1.2 & 2.05 & $0.25 \mathrm{M} / 3.8$ \\
\hline CT10 & ND & 1.5 & 2.4 & $0.25 M / 3.8$ \\
\hline CT11 & ND & 3.7 & 2.3 & $0.25 M / 3.8$ \\
\hline CT12 & 4.4 & 110 & 6.6 & $0.25 \mathrm{M} / 3.8$ \\
\hline CT13 & 3.3 & 80 & 1.6 & $0.25 M / 3.8$ \\
\hline CT14 & 3.8 & 80 & 1.8 & $0.25 \mathrm{M} / 3.8$ \\
\hline CT15 & 340 & 160 & 4.25 & $0.25 \mathrm{M} / 3.8$ \\
\hline CT16 & ND & 1 & 4.3 & $0.25 \mathrm{M} / 3.8$ \\
\hline CT17 & ND & 0.7 & 8.35 & $0.50 \mathrm{M} / 4.8$ \\
\hline CT18 & ND & 0.8 & 4.3 & ND \\
\hline CT19 & ND & 0.6 & 5.05 & ND \\
\hline
\end{tabular}

${ }^{\mathrm{a} F e e d / l o a d / r a f f i n a t e .}$

${ }^{b}$ Elution of conversion solution for cation-exchange resin.

${ }^{\mathrm{c}}$ No data.

\section{C77 ${ }^{254}$ Es AHIB Column 2}

Centrifuge tubes $11,12,13$, and 14 were put aside for the final cation-exchange column. The presence of ${ }^{252} \mathrm{Cf}$ still in CT15 indicated that there was a need to run a second AHIB column to separate the ${ }^{252} \mathrm{Cf}$ and einsteinium isotopes. The second AHIB column was prepared identical to the first AHIB column, consisting of a water-jacketed column with a $1.5 \mathrm{~mL}$ bed volume of AG50W-X8 (200-400) cation-exchange resin. CT15 needed to be brought to a concentration of around $2 M$, so $0.638 \mathrm{~mL}$ of $2 M \mathrm{HCl}$ was added to CT15. CT15 was loaded and pressurized through the column at a rate of 3.5 seconds per drop. The procedures listed in Section 2.2.2. were also followed for conversion of the column resin, rinsing, and stripping the product for the second AHIB column. Table 32 displays the dose rates and volumes of the centrifuge tubes and FLR bottles collected during the second AHIB column run. 
Table 32. Dose rates and volumes of centrifuge tubes 20-31 after second AHIB column

\begin{tabular}{c|c|c|c}
\hline \multirow{2}{*}{ Item } & $\begin{array}{c}\text { Dose Rate } \\
\text { Gamma, } \\
\text { mR/h }\end{array}$ & Volume, $\mathbf{m L}$ & [AHIB]/pH \\
\cline { 2 - 3 } & 2.0 & 12 & ND $^{\text {c }}$ \\
\hline FLR1 $^{\mathrm{a}}$ & 1.6 & 11 & $\mathrm{ND}$ \\
\hline FLR2 $^{\mathrm{a}}$ & 1.4 & 27 & $\mathrm{ND}$ \\
\hline CONVERSION $^{\mathrm{b}}$ & 0.9 & 11 & $\mathrm{ND}$ \\
\hline CT20 & 0.9 & 5.5 & $0.25 \mathrm{M} / 3.8$ \\
\hline CT21 & 0.8 & 1.6 & $0.25 \mathrm{M} / 3.8$ \\
\hline CT22 & 0.7 & 1.6 & $0.25 \mathrm{M} / 3.8$ \\
\hline CT23 & 0.6 & 9.3 & $0.25 \mathrm{M} / 3.8$ \\
\hline CT24 & 0.7 & 2.1 & $0.25 \mathrm{M} / 3.8$ \\
\hline CT25 & 0.7 & 4.05 & $0.25 \mathrm{M} / 3.8$ \\
\hline CT26 & 0.9 & 7.5 & $0.25 \mathrm{M} / 3.8$ \\
\hline CT27 & 3.2 & 8.5 & $0.25 \mathrm{M} / 3.8$ \\
\hline CT28 & 8.0 & 5.1 & $0.25 \mathrm{M} / 3.8$ \\
\hline CT29 & 60 & 1.4 & $0.50 \mathrm{M} / 4.8$ \\
\hline CT30 & 110 & 5.2 & $0.50 \mathrm{M} / 4.8$ \\
\hline CT31 & & & \\
\hline
\end{tabular}

${ }^{\mathrm{a} F e e d / l o a d / r a f f i n a t e .}$

${ }^{b}$ Elution of conversion solution for cation-exchange resin.

cNo data.

\section{C77 ${ }^{254}$ Es AHIB Column 3}

Centrifuge tubes 28, 29, 30, and 31 were kept for a third AHIB column. Like the first AHIB column, the remainder of the ${ }^{252} \mathrm{Cf}$ was not separated from the einsteinium isotopes; consequently, a third AHIB column was necessary at this point. The third AHIB column was prepared identically to the first and second AHIB columns, with a $1.5 \mathrm{~mL}$ bed volume of AG50W-X8 (200-400) cation-exchange resin. Centrifuge tubes 28, 29,30 and 31 were consolidated and $3 \mathrm{~mL}$ of $2 \mathrm{M} \mathrm{HCl}$ was added to the consolidated centrifuge tubes to adjust the acidity. After rinsing the column with water and $0.1 \mathrm{M} \mathrm{HCl}$, the consolidated centrifuge tubes were loaded onto the column and pressurized through at a rate of 2 seconds per drop. The procedures listed in Section 2.2.2. were also followed for conversion of the column resin, rinsing, and stripping the product for the third AHIB column. Table 33 displays the dose rates and volumes of the centrifuge tubes and FLR bottles collected during the third AHIB column run. 
Table 33. Dose rates and volumes of centrifuge tubes 32-45 after third AHIB column

\begin{tabular}{|c|c|c|c|}
\hline \multirow[b]{2}{*}{ Item } & Dose Rate & \multirow[b]{2}{*}{ Volume, mL } & \multirow[b]{2}{*}[\mathrm{AHIB}]{$/ \mathbf{p H}$} \\
\hline & $\begin{array}{c}\text { Gamma, } \\
\mathrm{mR} / \mathrm{h}\end{array}$ & & \\
\hline FLR $^{a}{ }^{a}$ & 2.0 & 31 & $\mathrm{ND}^{\mathrm{C}}$ \\
\hline CONVERSION $^{\mathrm{b}}$ & 1.3 & 30 & ND \\
\hline CT32 & 0.75 & 10.6 & $0.25 \mathrm{M} / 3.8$ \\
\hline CT33 & 0.8 & 4.3 & $0.25 \mathrm{M} / 3.8$ \\
\hline СТ34 & 1.0 & 2.7 & $0.25 M / 3.8$ \\
\hline СТ35 & 0.9 & 2.9 & $0.25 \mathrm{M} / 3.8$ \\
\hline СТ36 & 1.0 & 1.8 & $0.25 \mathrm{M} / 3.8$ \\
\hline СT37 & 6.0 & 5.8 & $0.25 M / 3.8$ \\
\hline СТ38 & 33 & 5.2 & $0.25 \mathrm{M} / 3.8$ \\
\hline СТ39 & 36 & 5.4 & $0.25 M / 3.8$ \\
\hline CT40 & 12 & 4.8 & $0.25 \mathrm{M} / 3.8$ \\
\hline CT41 & 16 & 3.3 & $0.25 \mathrm{M} / 3.8$ \\
\hline CT42 & 12 & 2.5 & $0.25 \mathrm{M} / 3.8$ \\
\hline CT43 & 3.7 & 2.7 & $0.25 M / 3.8$ \\
\hline CT44 & 2.0 & 2.1 & $0.25 \mathrm{M} / 3.8$ \\
\hline CT45 & 40 & 7.6 & $0.50 \mathrm{M} / 4.8$ \\
\hline
\end{tabular}

${ }^{\mathrm{a} F e e d / l o a d / r a f f i n a t e .}$

bElution of conversion solution for cation-exchange resin.

'No data.

\section{C77 ${ }^{254}$ Es AHIB Column 4}

Centrifuge tubes 37, 38, and 39 from the third AHIB column were chosen for a final AHIB column to separate the remainder of ${ }^{252} \mathrm{Cf}$ and ${ }^{249} \mathrm{Cf}$ after analysis of samples. Centrifuge tube 11 from the first AHIB column was also chosen to go through the final AHIB column to remove any daughter ingrowths of ${ }^{249} \mathrm{Bk}$ and ${ }^{249} \mathrm{Cf}$. Centrifuge tubes $11,37,38$, and 39 were consolidated into a poly bottle labeled "Consolidated Es Solution." Each centrifuge tube was rinsed twice with $\sim 1 \mathrm{~mL}$ of $0.25 \mathrm{M} \mathrm{HCl}$ each, which was added to the poly bottle. The volume of the poly bottle was $\sim 32 \mathrm{~mL}$. The fourth AHIB column was prepared with a different outer and inner diameter than the first three AHIB columns. A smaller outer diameter $(6 \mathrm{~mm})$ and inner diameter $(4 \mathrm{~mm})$ were used to achieve a cleaner separation of Es and Cf. The column consisted of a $1.5 \mathrm{~mL}$ bed volume of AG50W-X8 (200-400) cation-exchange resin. Around $1.3 \mathrm{~mL}$ of $6 \mathrm{M} \mathrm{HCl}$ was added to the consolidated Es solution to adjust the acidity to $\sim 0.3 \mathrm{M}$. After rinsing with $0.1 \mathrm{M} \mathrm{HCl}$, the product solution was added to the reservoir and pressurized through the column at a rate of 2 seconds per drop. The procedures listed in Section 2.2.2. were followed for conversion of the column resin, rinsing, and stripping the product for the fourth AHIB column. Table 34 displays the dose rates and volumes of the centrifuge tubes and FLR bottles collected during the fourth AHIB column run. 
Table 34. Dose rates and volumes of centrifuge tubes 46-60 after fourth AHIB column

\begin{tabular}{c|c|c|c|c}
\hline \multirow{2}{*}{ Item } & \multicolumn{2}{|c|}{ Dose Rate } & \multirow{2}{*}{ Volume, $\mathbf{~ m L}$} & [AHIB]/pH \\
\cline { 2 - 3 } & $\begin{array}{c}\text { Neutron, } \\
\mathbf{m r e m} / \mathbf{h}\end{array}$ & $\begin{array}{c}\text { Gamma, } \\
\mathbf{m R} / \mathbf{h}\end{array}$ & $\mathbf{2}$ & $\mathrm{ND}^{\mathrm{c}}$ \\
\hline FLR $^{\mathrm{a}}$ & $\mathrm{ND}$ & $\mathrm{ND}$ & 25 & $\mathrm{ND}$ \\
\hline CONVERSION $^{\mathrm{b}}$ & $\mathrm{ND}$ & $\mathrm{ND}$ & 3.0 & $0.25 \mathrm{M} / 3.8$ \\
\hline CT46 $^{*}$ & 2.1 & 7.9 & 1.4 & $0.25 \mathrm{M} / 3.8$ \\
\hline CT47 & 2.4 & 17 & 3.4 & $0.25 \mathrm{M} / 3.8$ \\
\hline CT48 & 3.1 & 99 & 2.1 & $0.25 \mathrm{M} / 3.8$ \\
\hline CT49 & 2.9 & 60 & 1.9 & $0.25 \mathrm{M} / 3.8$ \\
\hline CT50 & 3.3 & 39 & 2.0 & $0.25 \mathrm{M} / 3.8$ \\
\hline CT51 & 4.5 & 19 & 1.9 & $0.25 \mathrm{M} / 3.8$ \\
\hline CT52 & 5.0 & 9.0 & 1.7 & $0.25 \mathrm{M} / 3.8$ \\
\hline CT53 & 5.9 & 6.0 & 1.9 & $0.25 \mathrm{M} / 3.8$ \\
\hline CT54 & 6.0 & 8.0 & 1.8 & $0.25 \mathrm{M} / 3.8$ \\
\hline CT55 & 4.1 & 9.0 & 1.8 & $0.25 \mathrm{M} / 3.8$ \\
\hline CT56 & 3.7 & 9.0 & 1.9 & $0.25 \mathrm{M} / 3.8$ \\
\hline CT57 & 2.5 & 10 & 2.1 & $0.25 \mathrm{M} / 3.8$ \\
\hline CT58 & 2.2 & 10 & 3.8 & $0.50 \mathrm{M} / 4.8$ \\
\hline CT59 & 2.1 & 185 & 4.8 & $\mathrm{ND}$ \\
\hline CT60 & 2.0 & 1.5 & & \\
\hline
\end{tabular}

a Feed/load/raffinate.

${ }^{b}$ Elution of conversion solution for cation-exchange resin.

'No data.

\section{C77 ${ }^{254}$ Es Final Cleanup Column}

Centrifuge tubes 48 and 49 from the final AHIB column were chosen for a final cation-exchange column to separate the AHIB from the ${ }^{254} \mathrm{Es}$ product. Centrifuge tubes 48 and 49 were consolidated into centrifuge tube 48 , and $1.65 \mathrm{~mL}$ of $1.0 \mathrm{M} \mathrm{HCl}$ was used to adjust the acidity between 0.1 and $0.3 \mathrm{M} \mathrm{HCl}$. The column consisted of $10 \mathrm{~mL}$ reservoir micro-glass column filled with a $1.5 \mathrm{~mL}$ bed volume of AG50W-X4 (200400) $\mathrm{H}^{+}$cation-exchange resin. The inner diameter of the column is $4 \mathrm{~mm}$, and the outer diameter of the column is $6 \mathrm{~mm}$. After the column was conditioned with water and $0.1 \mathrm{M} \mathrm{HCl}$, the consolidated product solution was added to the reservoir and pressurized through the column at a rate of 3-4 seconds per drop. The procedure listed in Section 2.2.3 was followed for the rinsing and stripping of the product. Table 35 displays the dose rates and volumes of the centrifuge tubes and FLR bottles collected during the final cationexchange column run. 
Table 35. Dose rates and volumes of centrifuge tubes 61-66 after final cation-exchange column

\begin{tabular}{c|c|c|c}
\hline \multirow{2}{*}{ Item } & \multicolumn{2}{|c|}{ Dose Rate } & \multirow{2}{*}{ Volume, $\mathbf{~ L}$} \\
\cline { 2 - 3 } & $\begin{array}{c}\text { Neutron, } \\
\mathbf{m r e m} / \mathbf{h}\end{array}$ & $\begin{array}{c}\mathbf{G a m m a}, \\
\mathbf{m R} / \mathbf{h}\end{array}$ & \\
\hline CT61 & 1.7 & 1.4 & ND \\
\hline CT62 & 1.6 & 1.6 & 10 \\
\hline CT63 & 1.5 & 1.7 & 1.5 \\
\hline CT64 & 1.6 & 1.5 & 1.5 \\
\hline CT65 & 290 & ND & 6.1 \\
\hline CT66 & 1.6 & 0.1 & 5.7 \\
\hline
\end{tabular}

Centrifuge tube 65 was brought to dryness and allowed to cool under an argon sweep. Three drops of hydrogen peroxide were then added to the centrifuge tube to remove any organic material that could have followed the product through the column. Bubbles were noted before adding heat. The centrifuge tube was brought back to dryness and allowed to cool again. Around $3 \mathrm{~mL}$ of $2 \mathrm{M} \mathrm{HCl}$ were dispensed into the centrifuge tube, and an analytical sample was prepared and diluted from the solution to be bagged out of the glovebox. The rest of the solution from centrifuge tube 65 was used for dispensing to customers. Table 36 displays the analysis of the final ${ }^{254}$ Es product.

Table 36. Analysis of ${ }^{254}$ Es solution after final cleanup procedures

\begin{tabular}{c|c}
\hline Isotope & Mass, $\boldsymbol{\mu g}$ \\
\hline${ }^{254} \mathrm{Es}$ & $1.08 \mathrm{E}+00$ \\
\hline${ }^{253} \mathrm{Es}$ & $6.28 \mathrm{E}+00$ \\
\hline${ }^{252} \mathrm{Cf}$ & $2.00 \mathrm{E}-05$ \\
\hline
\end{tabular}

Table 37 displays the dispensing and shipping details for each customer for C77. Each aliquot of ${ }^{254}$ Es was dried down as a chloride salt for shipment, except the shipment to Japan Atomic Energy Agency, which was dried down as a nitrate salt.

Table 37. Dispensing and shipping details of ${ }^{254}$ Es solution for C77

\begin{tabular}{|c|c|c|c|c|c|}
\hline Customer & $\begin{array}{c}\text { Date } \\
\text { Shipped }\end{array}$ & ${ }^{254} \mathrm{Es}, \mu \mathrm{g}$ & ${ }^{253} \mathrm{Es}, \mu \mathrm{g}$ & ${ }^{252} \mathrm{Cf}, \boldsymbol{\mu g}$ & Packaging \\
\hline $\begin{array}{c}\text { Florida State } \\
\text { University }\end{array}$ & $\begin{array}{c}\text { June 1, } \\
2017\end{array}$ & $1.80 \mathrm{E}-02$ & $8.00 \mathrm{E}-02$ & $3.00 \mathrm{E}-04$ & $\begin{array}{c}3 \mathrm{~mL} \text { conical } \\
\text { vial }\end{array}$ \\
\hline $\begin{array}{l}\text { Colorado } \\
\text { School of } \\
\text { Mines }\end{array}$ & $\begin{array}{c}\text { June 7, } \\
2017\end{array}$ & $7.90 \mathrm{E}-03$ & $3.00 \mathrm{E}-02$ & $1.50 \mathrm{E}-04$ & $\begin{array}{c}3 \mathrm{~mL} \text { conical } \\
\text { vial }\end{array}$ \\
\hline $\begin{array}{l}\text { Japan } \\
\text { Atomic } \\
\text { Energy } \\
\text { Agency }\end{array}$ & $\begin{array}{c}\text { October 1, } \\
2017\end{array}$ & $3.70 \mathrm{E}-01$ & $3.60 \mathrm{E}-02$ & $1.00 \mathrm{E}-02$ & $\begin{array}{c}3 \mathrm{~mL} \text { conical } \\
\text { vial }\end{array}$ \\
\hline
\end{tabular}




\subsubsection{Lanthanide Contaminants}

After the shipment to Japan Atomic Energy Agency, amounts of ${ }^{160} \mathrm{~Tb}$ and stable ${ }^{159} \mathrm{~Tb}$ were observed in the ${ }^{254}$ Es sample sent, which can interfere with ${ }^{254}$ Es target fabrication. For the next campaign separating ${ }^{254} \mathrm{Es}$, an actinide/lanthanide separation will be necessary after the hot cell processing because the ${ }^{254} \mathrm{Es}$ cut does not undergo the Berkex extraction process for further lanthanide separation. This can be accomplished through an actinide/lanthanide separation column using TEVA resin (Eichrom) with an ammonium thiocyanate reagent.

\subsubsection{2. ${ }^{250} \mathrm{Bk}$ Discussion}

Throughout the AHIB column runs for ${ }^{254} \mathrm{Es}$, separation was believed to not have been achieved on the first three AHIB columns because of elevated beta dose levels from ${ }^{249} \mathrm{Bk}$, a strong beta emitter. After the fourth column, the samples were left to decay for 24 hours before analysis. Since one of the decay daughters for ${ }^{254} \mathrm{Es}$ is ${ }^{250} \mathrm{Bk}$, the beta dose levels were falsely elevated by ${ }^{250} \mathrm{Bk}$, and these levels were believed to have been ${ }^{249} \mathrm{Bk}$. After waiting 24 hours to allow the short-lived daughter products like ${ }^{250} \mathrm{Bk}$ to decay, the beta dose levels were decreased, showing a clean separation of ${ }^{254} \mathrm{Es}$ from the other isotopes. The issue of ${ }^{250} \mathrm{Bk}$ contributing to ${ }^{249} \mathrm{Bk}$ beta levels is only problematic with microgram quantities of ${ }^{254} \mathrm{Es}$ and ${ }^{249} \mathrm{Bk}$ because ${ }^{250} \mathrm{Bk}$ beta levels will only contribute a small amount to the overall beta doses of ${ }^{249} \mathrm{Bk}$. When working with microgram quantities of ${ }^{254} \mathrm{Es}$, it is necessary to let the short-lived daughter products decay for 24 hours before determining if the separation was successful.

\subsubsection{Attempted ${ }^{257} \mathbf{F m}$ Recovery}

A small fraction of ${ }^{257} \mathrm{Fm}$ was recovered from the hot cell separation steps for C77. If separated and purified, the ${ }^{257} \mathrm{Fm}$ could be used for general fermium chemistry research and heavy element research. The ${ }^{257} \mathrm{Fm}$ sample (CXES-314, cut 3) was expected to contain $<1$ pg of ${ }^{257} \mathrm{Fm},<1$ pg of ${ }^{254} \mathrm{Es}$, and $\sim 0.25 \mu \mathrm{g}$ of ${ }^{252} \mathrm{Cf}$. The ${ }^{257} \mathrm{Fm}$ cut was transferred to a new poly bottle in the hot cells after separation in preparation for bagging into a glovebox, and the acidity was adjusted to $\sim 0.3 \mathrm{M}$ with concentrated $\mathrm{HNO}_{3}$. The final volume was $\sim 60 \mathrm{~mL}$. Once the solution was transferred to a glovebox, an initial cation-exchange cleanup column was used to separate out any metal contaminants from the hot cell separation and to concentrate the ${ }^{257} \mathrm{Fm}$ product. The column consisted of a $1.5 \mathrm{~mL}$ bed volume of AG50W-X4 (200-400) strong cation-exchange resin. The outer diameter of the column was $6 \mathrm{~mm}$, and the inner diameter of the column was $4 \mathrm{~mm}$. Centrifuge tube 35, with a dose rate of $20 \mathrm{mR} / \mathrm{h}$ for gamma, $108 \mathrm{mR} / \mathrm{h}$ for beta/gamma, and $100 \mathrm{mrem} / \mathrm{h}$ for neutron was recovered from the cation-exchange column and was used in an AHIB column. The AHIB column consisted of a water-jacketed glass column of AG50W-X8 (200-400) strong cation-exchange resin. After centrifuge tube 35 was ran through the AHIB column, none of the samples gathered contained enough ${ }^{257} \mathrm{Fm}$ observed by gamma, alpha, and mass spectrometry to continue the separation process. 


\section{INSTRUMENTATION}

The following instrumentation was used to obtain spectroscopic data for Production Campaigns 74-77:

- Perkin Elmer TriCarb 5110TR for Liquid Scintillation Analysis

- Protean MPC-2000 Gas Flow Proportional Counter for Gross Alpha

- Canberra Model 7401 Alpha Spectrometer for Alpha Spectroscopy

- High Purity Germanium Detectors (various vendors) for Gamma Spectroscopy

- Neutron was counted with an in-house detector.

- Alpha and gamma spectrums were processed using Canberra Genie2K Acquisition and Analysis Software.

Dose rates were obtained using a Ludlum Model 9-4 Ion Chamber with a retractable beta shield and taken on contact through the glove port (Type of glove: Hypalon ${ }^{\circledR}$, ambidextrous, 8" cuff, Length/Gauge: $32 " / 15$ mil, Size 10.50) for all samples. 


\section{CONCLUSION}

The isolation of ${ }^{249} \mathrm{Bk}$ and ${ }^{254} \mathrm{Es}$ is of great importance to continue the investigations of berkelium and einsteinium chemical properties and the continuation of super heavy element research. The chemical processing steps for the final purification of ${ }^{249} \mathrm{Bk}$ and ${ }^{254} \mathrm{Es}$ were discussed throughout the ${ }^{252} \mathrm{Cf}$ Production Campaigns, along with a summary of the hot cell separation steps for the ${ }^{252} \mathrm{Cf}$ campaign itself. A summary of each of the ${ }^{252} \mathrm{Cf}$ Production Campaigns $74-77$ was discussed in length for ${ }^{249} \mathrm{Bk}$ and ${ }^{254}$ Es production. Separating ${ }^{257} \mathrm{Fm}$ in $\mathrm{C} 77$ was attempted but was not successful due to such minimal amounts of the isotope recovered. Table 38 below gives an overall summary of each production campaign.

Table 38. Summary of purified ${ }^{249} \mathrm{Bk}$ and ${ }^{254} \mathrm{Es}$ harvested in $\mathrm{Cf} \mathrm{C} 74$ through $\mathrm{C} 77$

\begin{tabular}{c|c|c|c}
\hline $\begin{array}{c}\text { Production } \\
\text { Campaign }\end{array}$ & Year & $\begin{array}{c}{ }^{249} \mathbf{B k} \\
\text { Harvested, } \mathbf{m g}\end{array}$ & $\begin{array}{c}{ }^{254} \text { Es Harvested, } \\
\boldsymbol{\mu g}\end{array}$ \\
\hline 74 & $2008-2009$ & $2.22 \mathrm{E}+01$ & N/A \\
\hline 75 & $2011-2012$ & $2.66 \mathrm{E}+01$ & N/A \\
\hline 76 & $2014-2015$ & $1.35 \mathrm{E}+01$ & N/A \\
\hline 77 & $2016-2017$ & $1.03 \mathrm{E}+01$ & $1.08 \mathrm{E}+00$ \\
\hline
\end{tabular}




\section{REFERENCES}

[1] Thompson, S. G., A. Ghiorso, and G. T. Seaborg. "The New Element Berkelium (Atomic Number 97).” Physical Review 80, no. 5 (December 1, 1950): 781-89. doi:10.2172/4421999.

[2] Oganessian, Yu. Ts., F. Sh. Abdullin, P. D. Bailey, D. E. Benker, M. E. Bennett, S. N. Dmitriev, J. G. Ezold, J. H. Hamilton, R. A. Henderson, M. G. Itkis, Yu. V. Lobanov, A. N. Mezentsev, K. J. Moody, S. L. Nelson, A. N. Polyakov, C. E. Porter, A. V. Ramayya, F. D. Riley, J. B. Roberto, M. A. Ryabinin, K. P. Rykaczewski, R. N. Sagaidak, D. A. Shaughnessy, I. V. Shirokovsky, M. A. Stoyer, V. G. Subbotin, R. Sudowe, A. M. Sukhov, Yu. S. Tsyganov, V. K. Utyonkov, A. A. Voinov, G. K. Vostokin, and P. A. Wilk. "Synthesis of a New Element with Atomic Number Z=117." Physical Review 104, no. 14 (April 09, 2010). doi:10.1103/physrevlett.104.142502.

[3] Ghiorso, A., S. G. Thompson, G. H. Higgins, G. T. Seaborg, M. H. Studier, P. R. Fields, S. M. Fried, H. Diamond, J. F. Mech, G. L. Pyle, J. R. Huizenga, A. Hirsch, W. M. Manning, C. I. Browne, H. L. Smith, and R. W. Spence. "New Elements Einsteinium and Fermium, Atomic Numbers 99 and 100." Physical Review 99, no. 3 (June 20, 1955): 1048-049. doi:10.1103/physrev.99.1048.

[4] Meierfrankenfeld, D., A. Bury, and M. Thoennessen. "Discovery of Scandium, Titanium, Mercury, and Einsteinium Isotopes.” Atomic Data and Nuclear Data Tables, September 9, 2010.

[5] Phillips, L., R. Gatti, A. Chesne, L. Muga, and S. Thompson. "Discovery of a New Mendelevium Isotope.” Physical Review Letters 1, no. 6 (August 21, 1958): 215-17. doi:10.1103/physrevlett.1.215.

[6] Smith, H. Louise, and Darleane C. Hoffman. "Ion-exchange Separations of the Lanthanides and Actinides by Elution with Ammonium Alpha-hydroxy-isobutyrate." Journal of Inorganic and Nuclear Chemistry 3 (April 27, 1956): 243-47. doi:10.1016/0022-1902(56)80025-0.

[7] Silver, M. A., S. K. Cary, J. A. Johnson, R. E. Baumbach, A. A. Arico, M. Luckey, M. Urban, J. C. Wang, M. J. Polinski, A. Chemey, G. Liu, K.-W. Chen, S. M. Van Cleve, M. L. Marsh, T. M. Eaton, L. J. Van De Burgt, A. L. Gray, D. E. Hobart, K. Hanson, L. Maron, F. Gendron, J. Autschbach, M. Speldrich, P. Kogerler, P. Yang, J. Braley, and T. E. Albrecht-Schmitt. "Characterization of Berkelium(III) Dipicolinate and Borate Compounds in Solution and the Solid State." Science 353, no. 6302 (August 26, 2016). doi:10.1126/science.aaf3762. 


\section{ACKNOWLEDGMENTS}

Research supported by the Isotope Program, Office of Nuclear Physics of the US Department of Energy. ORNL is managed by UT-Battelle LLC, for the US Department of Energy under contract DE-AC0500OR22725. Special thanks to Dennis Benker, Porter Bailey, the Transuranium Analytical Laboratory personnel at ORNL, the technical and support staff at REDC, and the radiological protection support staff at ORNL. 